University of South Florida

DIGITAL COMMONS

Digital Commons @ University of

@ UNIVERSITY OF SOUTH FLORIDA

South Florida

$4-5-2016$

\title{
Human Health Risk Characterization of Petroleum Coke Calcining Facility Emissions
}

Davinderjit Singh

University of South Florida, josan90@gmail.com

Follow this and additional works at: https://digitalcommons.usf.edu/etd

Part of the Environmental Health and Protection Commons, Public Health Commons, and the Toxicology Commons

\section{Scholar Commons Citation}

Singh, Davinderjit, "Human Health Risk Characterization of Petroleum Coke Calcining Facility Emissions" (2016). USF Tampa Graduate Theses and Dissertations.

https://digitalcommons.usf.edu/etd/6391

This Thesis is brought to you for free and open access by the USF Graduate Theses and Dissertations at Digital Commons @ University of South Florida. It has been accepted for inclusion in USF Tampa Graduate Theses and Dissertations by an authorized administrator of Digital Commons @ University of South Florida. For more information, please contact digitalcommons@usf.edu. 
Human Health Risk Characterization of Petroleum Coke Calcining Facility Emissions

by

Davinderjit Singh

A dissertation submitted in partial fulfilment

of the requirements for the degree of

Doctor of Philosophy

with concentration in Toxicology and Risk Assessment

Department of Environmental \& Occupational Health

College of Public Health

University of South Florida

Major Professor: Raymond D. Harbison, Ph.D.

Giffe T. Johnson, Ph.D.

Marie Bourgeois, Ph.D.

Nicholas Hall, Ph.D.

Date of Approval:

April 1, 2016

Keywords: pet coke, calcined coke, black carbon, TEOM, petrochemical pollution

Copyright (c) 2016, Davinderjit Singh 


\section{DEDICATION}

To my wife, my sisters, sister-in-law and my mother. 


\section{ACKNOWLEDGMENTS}

I would like to express my sincere gratitude to my major advisor, Dr. Raymond Harbison. He has been a great guide and mentor since the first day of my doctoral education at USF. Thanks Dr. Ray. I am also grateful to all my committee members, Dr. Giffe Johnson, Dr. Marie Bourgeois, and Dr. Nicholas Hall for their valuable inputs, guidance, and suggestions on this project. Dr. Johnson has been a great teacher and a friend, offering invaluable knowledge through positive attitude and constructive approach. Dr. Marie played a pivotal role in my academic achievements at USF and Dr. Hall supported and guided me throughout the dissertation work. Lastly, I would like to thank my loving wife, Mona and my family for been a constant source of strength, comfort, and emotional support. 


\section{TABLE OF CONTENTS}

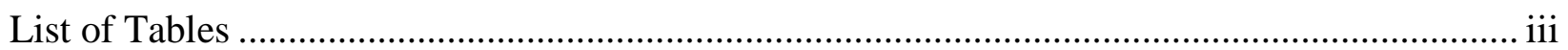

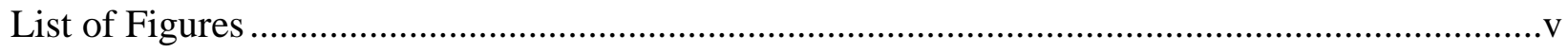

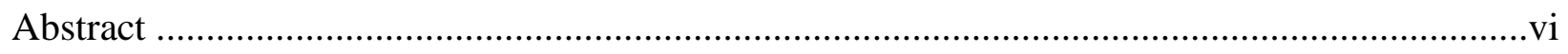

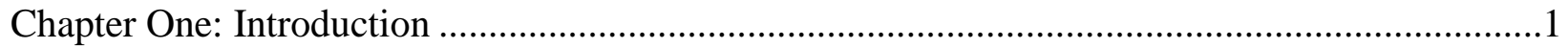

1.1 History of Calcined Coke Production .....................................................................

1.2 Physical and Chemical Properties of Green and Calcined Coke .................................4

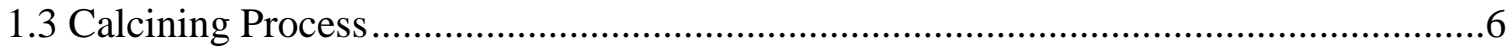

1.4 Uses of Green Coke and Calcined Coke ...................................................................

1.5 Variability in Emissions from Petrochemical and Calcining Industries ......................8

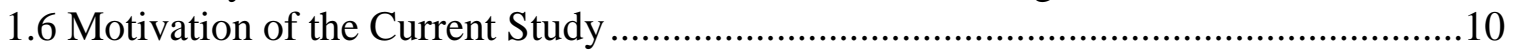

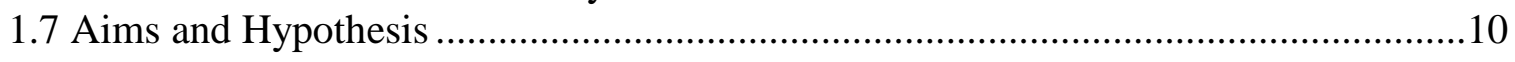

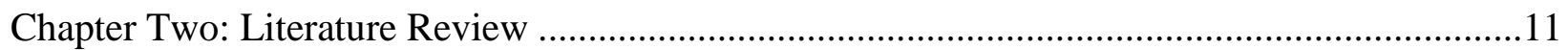

2.1 Pollutant Constituents and the Regulatory Standards .............................................11

2.1.1 Regulatory Standards for Particulate Matter (PM10) .................................12

2.1.2 Regulatory Standards for Gaseous (CO, NOx, $\left.\mathrm{SO}_{2}\right)$ Emissions..................16

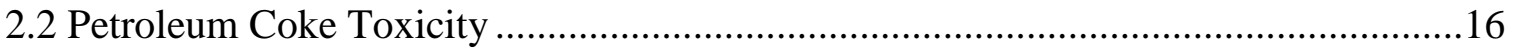

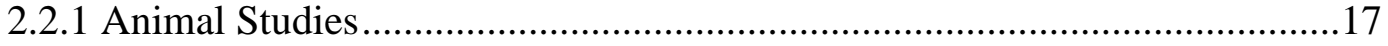

2.2.2 Occupational Studies .....................................................................19

2.3 Risk Assessed in Epidemiological Studies from Petrochemical Industries.................21

2.3.1 Petrochemical Industry and Pollutant Emissions.......................................21

2.3.2 Single Pollutant and Multiple Pollutant Exposure ......................................23

2.3.3 Petrochemical Industries and Study Protocols.........................................26

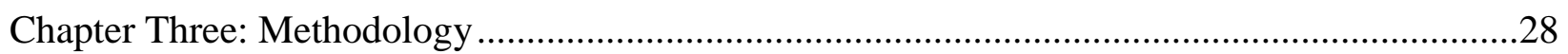

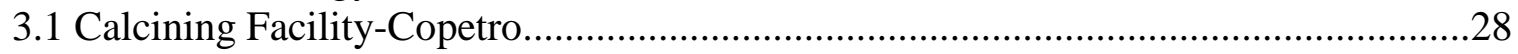

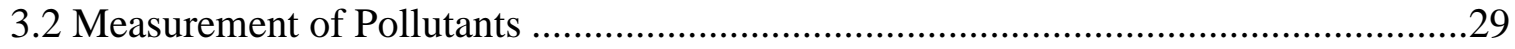

3.3 Analysis of Epidemiological Risk Assessment Studies..........................................

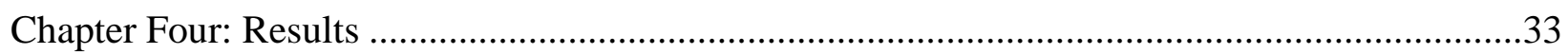

4.1 Particulate Matter Emissions form the Calcining Facility .......................................33

4.2 Black Carbon Emissions from the Calcining facility ...........................................42

4.3 Gaseous Emissions from the Calcining Facility ................................................. 43

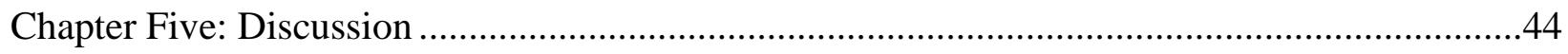

5.1 Particulate Matter from Calcining Process and Public Health Risks.........................44 
5.2 Gaseous Emissions from Calcination Process and Public Health Risks

5.3 Epidemiological Review: Health Risks from Petrochemical Emissions .....................46

5.4 Review of epidemiological Studies on Petrochemical Emissions ..............................48

5.5 Critique on Ambient Air Pollution Epidemiological Studies ...................................54

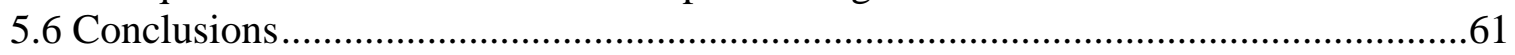

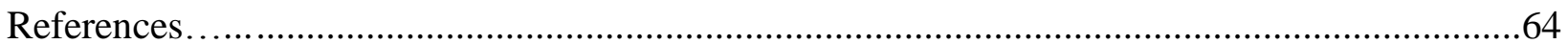




\section{LIST OF TABLES}

Table 1: Comparison Between Raw (Green) Coke and Calcined Coke

Table 2: Typical Specifications of the Calcined Petroleum Coke

Table 3: Applications to Green Petroleum Coke and Desired Quality of the Raw Coke 7

Table 4: National Ambient Air Quality Standards (NAAQS) for CO, $\mathrm{NO}_{2}, \mathrm{PM} 10$, and $\mathrm{SO}_{2} \ldots .12$

Table 5: Cohort Studies of Carcinogenic Potential of Coking Process in Workers 20

Table 6: 24-Hour PM10 Levels for Year 2008. .33

Table 7: $\quad$ 24-Hour PM10 Concentrations Measured by Hi-Vol and TEOM Monitors in 2009...34

Table 8: Analyses of 24-Hour PM10 Concentrations in 2009. .35

Table 9: Monthly 24-hour Average of PM10 for TEOM 3 for Time Period-1st Quarter 2009 Through 3rd Quarter 2014 .36

Table 10: Monthly 24-hour Average of PM10 for TEOM 4 for Time Period-1st Quarter 2009 Through 3rd Quarter 2014

Table 11: Monthly 24-hour Average of PM10 for TEOM 5 for Time Period-1st Quarter 2009 Through 3rd Quarter 2014

Table 12: PM10 Values Higher than the NAAQS Standard of $150 \mu \mathrm{g} / \mathrm{m}^{3}$

Table 13: Long-Term annual average PM10 Concentrations for Locations Near the Copetro ....42

Table 14: Modeled Ambient Air Concentrations. 
Table 15: Review of Epidemiological Studies on Petrochemical Emissions . 


\section{LIST OF FIGURES}

Figure 1: Crude Oil Processing and By-Products................................................................2

Figure 2: Different Types of Green Petroleum Coke.............................................................4

Figure 3: Calcination of Green Coke to Produce Calcined Coke ..............................................6

Figure 4: Percentage of Green Petroleum Coke Formed from Crude Oil ................................8

Figure 5: Copetro Calcining Facility Complex …........................................................28

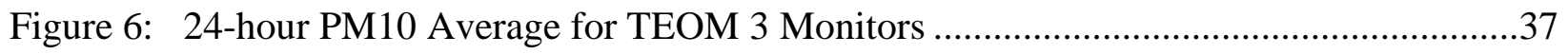

Figure 7: 24 -hour PM10 Average for TEOM 4 Monitors .....................................................38

Figure 8: 24 -hour PM10 Average for TEOM 5 Monitors ...................................................40

Figure 9: Quarterly Average of 24-hour PM10 Concentration for TEOM 3, 4, and 5 .............40

Figure 10: Black Carbon Monthly Average Concentration....................................................42 


\begin{abstract}
Calcined coke is a high quality carbon material produced by calcining green petroleum coke. Calcining is the process of heating green petroleum coke in a kiln to remove excess moisture, extract all remaining hydrocarbons, and modify the crystalline structure of the coke into a denser, electrically conductive product. The final product, calcined coke, is primarily used to make carbon anodes for the aluminum industry and recarburizing agent for industries such as the steel industry. If not appropriately controlled, the calcining process could lead to excess production of particulate emissions from either handling or storing of raw coke, or from the stack emissions during the production of calcined coke. Though calcined coke has shown low hazard potential in human populations due to low volatile content, there remains some public health concern regarding the emissions from these facilities. This study is designed to evaluate the emissions of petroleum coke calcining facility and assess the public health concern from the processes engaged in the handling and storage of green coke as well as from the calcining process. The ambient air levels were measured from a calcining facility and compared with the standards promulgated by USEPA. The results showed that pollutant contribution from the facility, measured by monitoring carbon fraction of the emissions, was de-minimis. The current research also studied whether the exposure levels and health risks specified in various epidemiological studies correlate with the standards promulgated by USEPA to protect public health from petrochemical emissions.
\end{abstract}




\section{CHAPTER ONE:}

\section{INTRODUCTION}

Calcined coke is a carbonaceous product produced from the thermal treatment of raw petroleum coke. It is a sponge like material used in the production of anodes and in the aluminum industry to conduct electricity due to its porous structure. It is the primary raw material for aluminum smelter anodes, and a source of energy or fuel for power plants and cement kilns.

The processing of crude oil produces various by-products including petroleum coke (Figure 1). Petroleum coke could broadly be categorized into green coke and calcined coke. Green petroleum coke, a black colored solid material, is produced from the thermal decomposition of heavy crude oil. When green coke is subjected to further thermal processing, i.e. removal of moisture and volatile matter, it results in the production of calcined coke (Figure 1). The primary difference between the green coke and calcined coke is in the proportion of constituent materials such as hydrocarbons, ash, and sulfur. Petroleum coke calcining involves multiple steps, including drying the raw coke, devolatization at high temperatures, and densification. The initial drying process is a time-temperature function and is conducted in an atmosphere devoid of oxygen. To obtain the desired coke properties of higher density and conductivity it is subjected to higher temperatures, up to $1400^{\circ} \mathrm{C}$. As mentioned, calcination of raw petroleum coke is done in two types of kiln, kettle kilns or rotary kilns. Whether heating of the raw materials indirectly (kettle kilns) or directly (rotary kilns) involves the use of pyro scrubber that is used to oxidize the carbon content of the raw petroleum coke 
including the volatile organic materials in the coke. Further decomposition of the coke results in the product that has high carbon to hydrogen ratio. This results in the final product that has very small amounts of volatile organic compounds, metals, ash, or gaseous pollutants in the discharged product. The process converts the raw coke into a sponge like product that is used in the production of anodes in the aluminum industry.

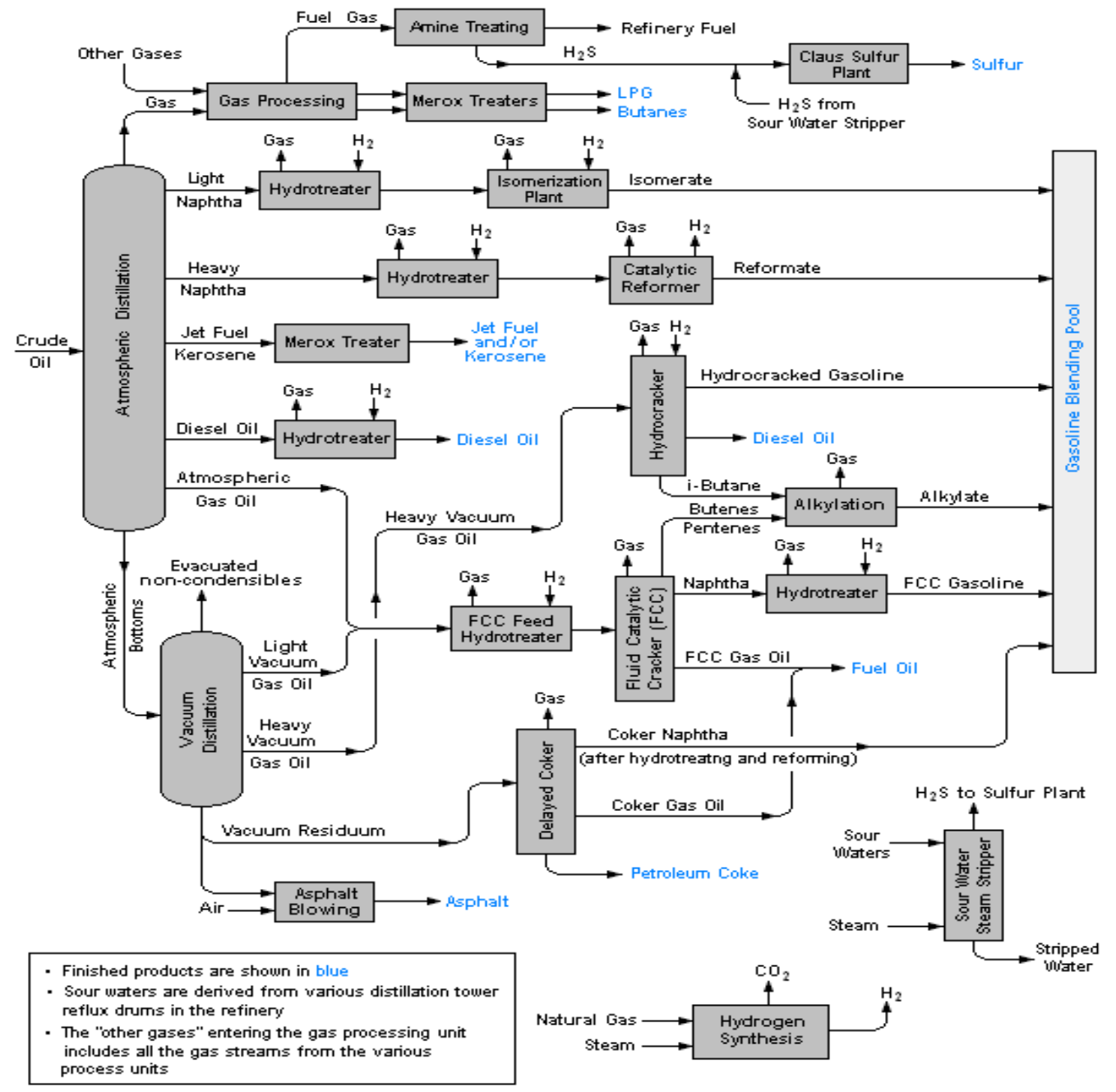

Source: CC BY-SA 3.0, http://creativecommons.org/licenses/by-sa/3.0/

Figure 1 Crude Oil Processing and By-Products 


\subsection{History of Calcined Coke Production}

The use of petroleum coke as a filler in various carbon products is dated back to 1860's. However, around 1920's there was a sudden surge in the production of green or calcined coke a byproduct with comparatively higher carbon content using the delayed coking process (Edwards et al., 2015). Since the inception of delayed coking process in 1920's, the methods to produce calcined coke have almost remained the same for many years. Now for over a century, calcined coke has proved to be an ideal raw material for carbon anodes used in the electrolysis process (Hall-Heroult electrolysis) due to its favorable properties such as high carbon content, sponge like character, cheap and economical, as well as easy availability. As of 2013, around 115 million Dry Metri Tonne (DMT) of green petroleum coke was produced but only $1 / 4^{\text {th }}$ of this raw material was used, highlighting the abundance and availability of raw material to produce the calcined coke.

There are primarily three processes used to produce petroleum coke; delayed coking, coking in fluidized bed without gasification, and coking in fluidized with gasification. The delayed calcined coke is the process, which on high temperatures converts the higher molecular weight hydrocarbons to low molecular weight carbons, which further undergo polymerization to produce a sponge-like high conducting material, green petroleum coke. Depending on the purity of this green petroleum coke, it could either be used as a fuel for power generation (higher sulfur (S) lower purity) or as a raw material in calcining industry for anodes, aluminum, and steel production (lower sulfur (S) higher purity). The green petroleum coke may be of three main types: needle coke, sponge coke, and shot coke (Figure 2). Needle coke (low S) is mainly used in arc furnaces for production of steel due to its low CTE (coefficient of thermal expansion). The sponge coke due to its intermediate CTE and high porosity is used in the anode production. Moreover, the porous structure of needle coke helps in adequate penetration during mixing and confers a strong property to the anode structure. The shot 
coke due to its high CTE and S content is used as a fuel and in titanium oxide applications (Edwards et al., 2015).

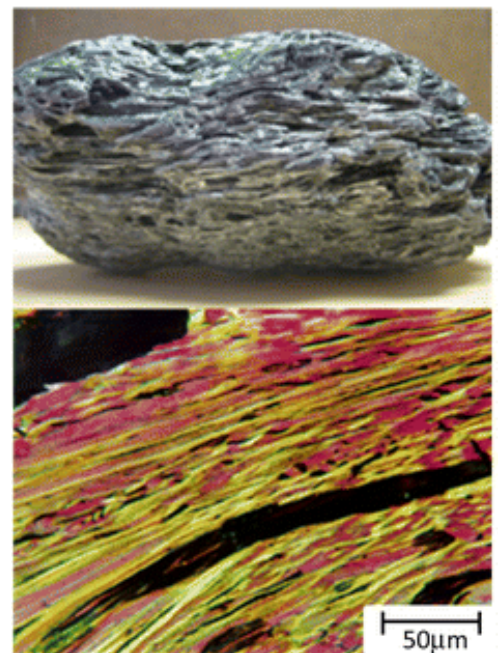

Needle Anisotropic

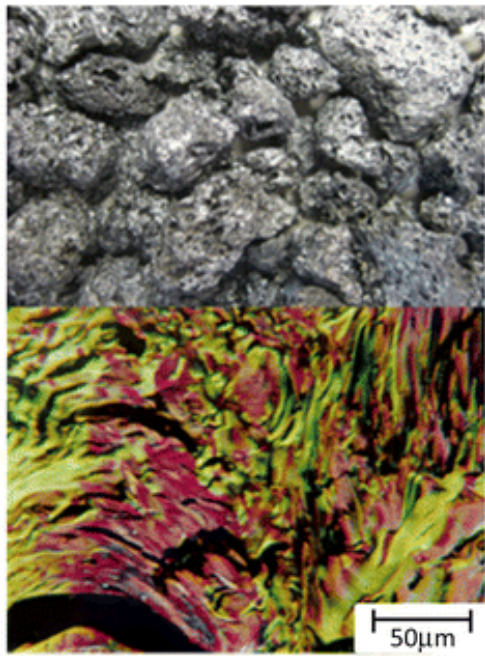

Sponge

Mixed

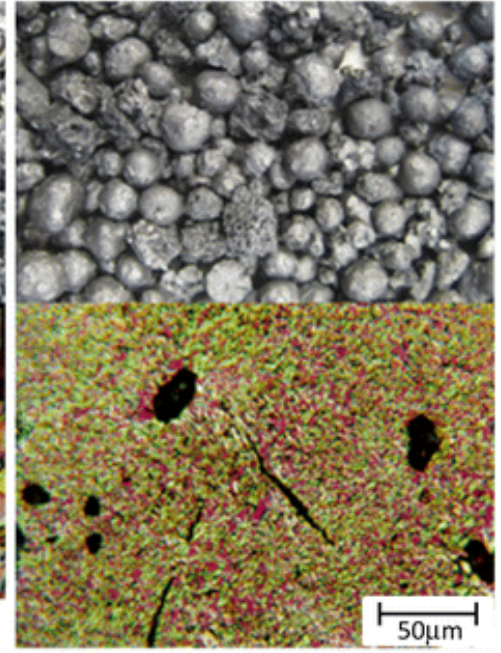

Shot

Isotropic

Figure 2 Different Types of Green Petroleum Coke (Edwards et al., 2015) Creative Commons Attribution License

In the calcining industries the green petroleum coke with low Sulfur content is then heat treated at very high temperatures for the production of anodes. The heating of green petroleum coke results in structural changes and hence a product with higher carbon content and conductivity, with low reactivity to $\mathrm{O}_{2}$ and $\mathrm{CO}_{2}$. This process also drives off the Volatile Matter (VM) and moisture content resulting in a high density product known as calcined coke.

\subsection{Physical and Chemical Properties of Green and Calcined Coke}

Green coke and calcined coke vary in terms of their physical and chemical properties. Generally, the properties of calcined coke are dependent on the source of raw green coke as well as the refining process used to produce calcined coke. The physical and chemical properties are generally determined on the basis of ash content, metallic impurities such as nickel and zinc, and presence of volatile matter and moisture. Green coke has higher percentage of volatile matter, 
moisture, and metal content compared to calcined coke (Table 1). Research indicates that the volatile content of raw green coke varies from $0.13-0.20 \%$ of the total coke weight and the moisture content varies from 0.28-0.33\% of total coke weight (Birghila et al., 2011).

Table 1 Comparison Between Raw (Green) Coke and Calcined Coke

\begin{tabular}{|l|l|l|}
\hline Composition & Green Coke & Calcined Coke \\
\hline Volatile Matter, \% & $9.0-10.5$ & $0.08-0.15$ \\
\hline Moisture, \% & $8.0-14.0$ & $0.2-0.4$ \\
\hline Ash content, \% & $0.09-0.14$ & $0.1-0.18$ \\
\hline Sulfur, ppm & $0.7-0.85$ & $0.7-0.78$ \\
\hline Nickel, ppm & $180-200$ & $200-220$ \\
\hline Iron, ppm & $80-120$ & $60-100$ \\
\hline Calcium, ppm & $20-40$ & $20-40$ \\
\hline Silicon, ppm & $40-80$ & $20-60$ \\
\hline
\end{tabular}

On the other hand, the calcined coke has low S content, low VM content, low metallic constituents, and lower ash content (Table 2). This type of coke is used in the aluminum industry for making anodes and in foundries as a carburizer. Some types of calcined coke have high ash content with more metallic impurities and are used as fuel rods for energy production.

Table 2 Typical Specifications of the Calcined Petroleum Coke

\begin{tabular}{|l|l|l|}
\hline Property & $\begin{array}{l}\text { Typical } \\
\text { Specification }\end{array}$ & Broader Specification \\
\hline Moisture, \% & 0.3 & 0.5 \\
\hline Ash, \% & 0.3 & 0.5 \\
\hline Sulfur, \% & 3 & 3.5 \\
\hline Nickel, ppm & 250 & 300 \\
\hline Iron, ppm & 300 & 400 \\
\hline Calcium, ppm & 200 & 250 \\
\hline Silicon, ppm & 250 & 300 \\
\hline
\end{tabular}




\subsection{Calcining Process}

The process of conversion of raw green coke to calcined coke involves multiple steps as shown in Figure 3. The initial step involves the transfer of raw coke into the calcining kilns, via the conveyer belts. Various types of kilns may be used for this step such as rotary kiln or hearth and shaft kiln. However, the rotary kilns are more common and are used worldwide but a few countries like China still use the shaft kilns (Hasanbeigi et al., 2013). The next step is heating of the petroleum coke (petcoke) at high temperatures in the kiln, between $1200{ }^{\circ} \mathrm{C}$ and $1350{ }^{\circ} \mathrm{C}\left(2192\right.$ to $\left.2462{ }^{\circ} \mathrm{F}\right)$ to remove moisture, drive off volatile materials, increase the density of the coke structure, increase the physical strength, and increase the electrical conductivity of the material. This process also tends to result in the production of exhaust gases and particulate emissions in the atmosphere. To help maintain high temperatures during this process, natural gas or oil is used as a fuel which is later replaced by the self-combustion of the hydrocarbons with the addition of oxygen.

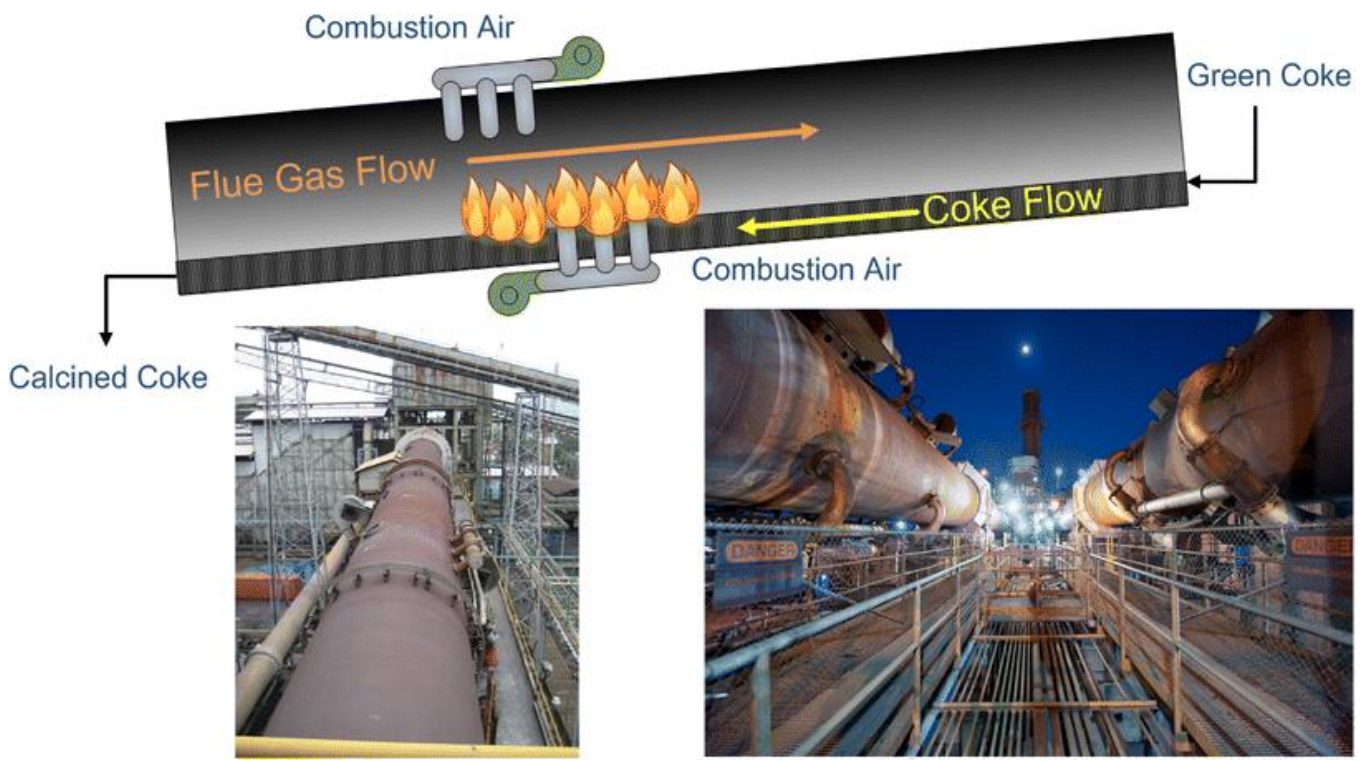

Figure 3 Calcination of Green Coke to Produce Calcined Coke (Edwards et al., 2015) Creative Commons Attribution License 
Finally, the last step involves cooling of the calcined coke from high temperatures to about $200^{\circ} \mathrm{C}$ within hours, after which it is carefully handled and safely transported to storage facilities via trucks, shipping, or trains.

\subsection{Uses of Green Coke and Calcined Coke}

Petroleum coke (raw material for calcined coke) is widely used throughout the world as a fuel in thermoelectric power plants and as a raw material for cement industry including steal and lime industries, pig iron industry, cement kiln and power plants (Table 3) (Santos et al., 2015). On the other hand, calcined coke is the exclusive raw material for the fabrication and the production of aluminum anodes, with aluminum industries utilizing about $75 \%$ of the total calcined coke. The calcined coke is also used as a recarburizing agent in steel industries, and in the production of titanium dioxide. Titanium dioxide is used in various household materials including paints, sunscreen, or as food coloring agents. The calcined coke is also used as a substitute for metallurgical coal in the production of coke batteries. A form of petcoke, needle coke, is the only compound that is used in the production of electrodes that are utilized in electric arc furnaces. Due to its low ash content, pet coke is also used in the glass and brick industries.

Table 3 Applications to Green Petroleum Coke and Desired Quality of the Raw Coke

\begin{tabular}{|c|c|}
\hline $\begin{array}{c}\text { Applications of the Green Coke } \\
\text { Raw material for calcination }\end{array}$ & Markets \\
\hline Carbon- based reducer & Pig iron, Iron alloys, Carbides \\
\hline Raw material for coke kiln & Foundry, Steel industries \\
\hline Fuel & Cement kiln, Lime industries, Power plants \\
\hline
\end{tabular}




\subsection{Variability in Emissions from Petrochemical and Calcining Industries}

"Petroleum industries" is a broad term referring to the storage, transfer or the processing of petroleum products (Figure 1 for listing of all the major processes occurring in a petroleum plant); and hence involves use of various different raw and processed products such as $2-3 \%$ of calcined coke and (Figure 4).

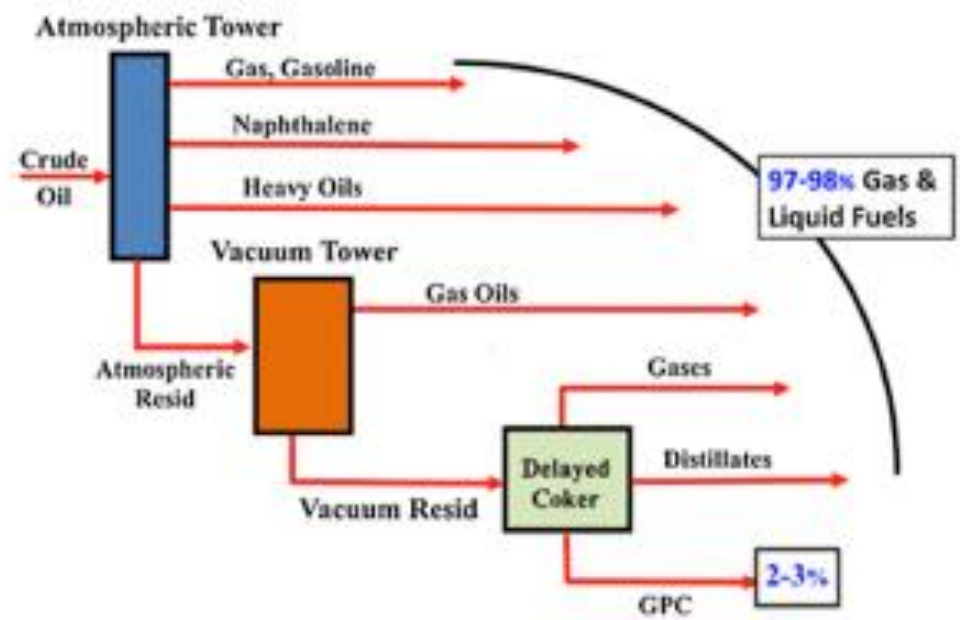

Figure 4 Percentage of Green Petroleum Coke Formed from crude oil (Edwards et al., 2015) Creative Commons Attribution License

Furthermore, each raw/ processed product involved in these industries has a varied level of hazard potential (see section above for details, Clark et al., 2013). The last few decades have seen a surge in the extraction of crude oil due to higher market demands for gasoline and diesel, further resulting in greater processing of crude oil and production of by-products such as petroleum coke.

On the other hand, the coke calcining industry usually refers to the standalone process of producing calcined coke from green coke. For most purposes, green coke is an inert substance and the health hazards assigned to green coke are mostly associated with the Particulate Matter (PM) exposures produced during calcination (McKee et al., 2014). The high temperatures required for the 
process of calcination and the further processing of the gases in a combustion chamber, sometimes referred to as a pyro scrubber, provides sufficient heat that eliminates the majority of the emissions including volatile organic compounds and combustible particles. This process can result in emission of pollutants such as sulfur impurities in the air if the process and the conditions in the facility are not controlled properly.

Though calcined coke has shown low hazard potential in human populations due to low volatile content, there remains some public health concern regarding the emissions from these facilities. Handling and storage of raw petcoke and calcined coke has the potential to produce particulate emissions due to the transfer of these materials and wind induced suspension of smaller particles. If not appropriately controlled, the calcination process could lead to the excess production of particulate emissions from either handling or storage of raw coke, or from the stack gases during the production of calcined coke.

Most of the epidemiological studies have analyzed the ambient PM and its association with acute respiratory effects including asthma, exacerbation of asthma symptoms, increase or decrease in medication use, hospital or emergency ward admissions. In addition, majority of these epidemiological studies examined the effect of mixture of pollutants from a "petrochemical" industry and its effect on individual concentration and health effects. Both co-pollutant and multipollutant methods have been utilized in the past to derive the exposure concentrations of such pollutants. Specifically, the studies examining the effect of multiple pollutants at a single period of time are plagued by various factors hampering the strength of association measured in the study. These include but are not limited to factors that affect pollutant inter and intra variations, unknown pollutant that may act as a confounder, multiple pollutants that may interact with each other and produce variable health effects, and exposure uncertainty. 


\subsection{Motivation of the Current Study}

This study was designed to evaluate the emissions of petroleum coke calcining facility and examine the public health concerns from the processes engaged in the handling and storage of green coke during the calcining process. Most of the previous studies have researched the risk from petroleum industries emissions and risk from calcining facility as a part of "petroleum industries" and not as a stand alone process. This research study is designed to characterize the risk specifically from calcining facility and processes involved in the facility.

\subsection{Aims and Hypothesis}

Aim 1: To examine whether the Particulate Matter generated from the calcining process in a petrochemical facility associated with any public health risks?

Hypothesis 1: We hypothesized that the Particulate Matter produced during the calcining process would not pose threat to the public health.

Aim 2: To examine whether the gaseous emissions of a calcining facility engaged in the handling and storage of green coke lead to any public health risks?

Hypothesis 2: We hypothesized that the gaseous emissions from the calcining facility would not adversely effect the health of the public community.

Aim 3: To examine whether the epidemiological studies investigating the effects of pollutant emissions from the petrochemical industries accurately represented the risk to the affected population, in terms of morbidity and mortality?

Hypothesis 3: We expect that past epidemiological studies adequately represent the risk associated with petroleum industries in the affected population. 


\section{CHAPTER TWO: \\ LITERATURE REVIEW}

\subsection{Pollutant Constituents and the Regulatory Standards}

The National Ambient Air Quality Standards (NAAQS) are set up by regulatory agencies that estimate potential magnitude of ambient air pollutant levels leading to adverse health effects (morbidity and premature mortality), on exposed population. The standards are developed by the Environmental Protection Agency (EPA) to understand the potential impact of various pollutants and assess the risk from those pollutants. NAAQS include primary and secondary standards. Primary standards are meant for protection of sensitive populations including children, asthmatics and older population. Secondary standards are helpful for public welfare including protection to animals, crops, and buildings. Such standards help in obtaining estimates in risk assessment from the ambient air pollutants on the human and animal population. The standards are set for six pollutants, known as criteria pollutants that are revised and reviewed periodically. Four criteria pollutants (PM10, $\mathrm{SO}_{2}$, $\mathrm{NO}_{2}$, and $\mathrm{CO}$ ) out of six were measured and compared for this research study. Table 4 shows the four criteria pollutants and regulatory standards used to compare with the measured concentration of the emissions from the calcining facility. 
Table 4 National Ambient Air Quality Standards (NAAQS) for CO, $\mathrm{NO}_{2}, \mathrm{PM}_{10}$, and $\mathrm{SO}_{2}$

\begin{tabular}{|c|c|c|c|c|}
\hline Pollutant & $\begin{array}{l}\text { Primary/ } \\
\text { Secondary }\end{array}$ & $\begin{array}{l}\text { Averaging } \\
\text { Time }\end{array}$ & Level & Form \\
\hline \multirow[t]{2}{*}{ Carbon Monoxide (CO) } & \multirow[t]{2}{*}{ Primary } & 8-hour & 9 ppm & \multirow{2}{*}{$\begin{array}{l}\text { Not to be exceeded more than once per } \\
\text { year }\end{array}$} \\
\hline & & 1-hour & $35 \mathrm{ppm}$ & \\
\hline \multirow[t]{2}{*}{ Nitrogen Dioxide } & Primary & 1-hour & $100 \mathrm{ppb}$ & $\begin{array}{l}\text { 98th percentile of 1-hour daily maximum } \\
\text { concentrations, averaged over } 3 \text { years }\end{array}$ \\
\hline & $\begin{array}{l}\text { Primary and } \\
\text { Secondary }\end{array}$ & Annual & $53 \mathrm{ppb}$ & Annual Mean \\
\hline $\begin{array}{l}\text { Particulate Matter } \\
\qquad \text { (PM10) }\end{array}$ & $\begin{array}{l}\text { Primary and } \\
\text { Secondary }\end{array}$ & 24-hour & $150 \mu \mathrm{g} / \mathrm{m}^{3}$ & $\begin{array}{l}\text { Not to be exceeded more than once per } \\
\text { year on average over } 3 \text { years }\end{array}$ \\
\hline \multirow[t]{2}{*}{ Sulfur Dioxide } & Primary & 1-hour & $75 \mathrm{ppb}$ & $\begin{array}{l}\text { 99th percentile of 1-hour daily maximum } \\
\text { concentrations, averaged over } 3 \text { years }\end{array}$ \\
\hline & Secondary & 3-hour & $0.5 \mathrm{ppm}$ & $\begin{array}{l}\text { Not to be exceeded more than once per } \\
\text { year }\end{array}$ \\
\hline
\end{tabular}

\subsubsection{Regulatory Standards for Particulate Matter (PM10)}

Particulate matter or PM is a mixture of particles and liquid droplets that are composed of multiple components including chemicals, metals, or dust particles. The PM is mostly classified on the basis of their aerodynamic properties since such properties ascertain the transport and removal of PM from air and govern the ability to deposit in the lungs. Particles are described according to their aerodynamic diameter, known as particle size. The potential to cause risk is directly proportional to the size and shape of the particles. There are two most commonly categorized types of PM. The particles with size range between 2.5 and 10 microns are known as "coarse particles" and those less than 2.5 microns are labelled as "Fine particles". The inhalation to such particles is a health concern since particles of less than 10 microns have the ability to travel over long distances 
and have the ability to lodge in deeper sections of the lungs with smaller size particles having more propensity to travel and deposit than the larger size particles. The smaller size particles largely consist of aerosol, metal particles, combustion emissions and organic vapors while the larger or coarse particles are largely composed of dust emissions from roads, agricultural and mining processes, and construction activity (WHO, 2005). The particles that are less than $2.5 \mu \mathrm{m}$ in diameter are more likely to result in greater health risk since they have the ability to lodge in the deeper sections of the lungs than PM10 particles. Shwartz et al. 1996 conducted a study on the effect of PM2.5 and PM10 on the daily mortality in six US cities for 8 years. The study showed that though positive association was observed for exposure to PM10 and PM2.5, the strongest association was observed for PM2.5 and $10 \mu \mathrm{g} / \mathrm{m}^{3}$ increase in PM2.5 was associated with $1.5 \%$ higher daily mortality. The study showed that particle size in the range of $2.5 \mu \mathrm{m}$ is more specifically associated with health effects than larger size particles. The study done by Pope et al. 2002 showed that health effects including cardiopulmonary effects and carcinogenic potential were higher for increased exposure to PM2.5 than other size particles and mortality was not significantly associated with exposure to coarse particles.

The health effects from the particulate emissions is dependent upon the chemical composition as well as the size of the particle. Combustion of petroleum and petroleum products may produce coarse particles from the non-combustible products such as ash, vaporized metals, and secondary particles from the mixture of gases $\left(\mathrm{SO}_{2}, \mathrm{NOx}\right)$ released during the petroleum processes (WHO, 2003). The Coarse particles may be produced by multiple activities including inadequate storage and handling of raw materials, crushing and grinding operations and activities from roads and construction nearby the petroleum industries. The majority of particulate emissions from the 
calcining facility are in the form of coarse particles with less propensity, than smaller fine particles, to travel over long distances and lesser ability to reach deeper parts of the lungs.

Adequate information about particulate emissions and gaseous pollutant from the calcining facility may help in characterizing the toxicological properties of petroleum coke and its constituents and further evaluate the potential health risks. Since 1960, public health agencies have tried to develop approaches to establish regulatory standards for the protection from pollutant exposure that may lead to adverse health effects. The standards have since then been more focused on inhalable particles than total suspended particles (TSP). The formulation of standards has also taken into account the long term and short term exposures and variable health effects from such exposures. The standards developed by National Ambient Air Quality Standards are based on available toxicological and epidemiological studies, with latest standards devised from about 200 epidemiological studies from US population and from laboratory studies conducted on PM. These standards are revised every five years to promulgate public health protection, with an adequate margin of safety (USEPA, 2006). While EPA has established short term exposure standards for both PM2.5 and PM10, for long term exposures, the standards are based on PM2.5 exposures rather than PM10 since controlling PM2.5 has been associated with higher exposure to total inhalable particles than PM10 (USEPA, 2006). In addition, WHO has framed Air Quality Guidelines (ACG) for exposures to PM and the safety values are derived from the lowest concentrations that were able to assign any statistically significant risk in the epidemiological studies. These studies provide a high level of margin of safety for health protection since different industrial processes require different sources and thus may produce varied quality and quantity of pollutant emissions. This approach is based on the thought that the regulatory standards are not meant to eliminate 'all' risks but represent an 'acceptable' risk margins. 
The epidemiological studies that are conducted on populations (both small and large) present with a conundrum of observing the exposure values, with statistical significance, above which the adverse effects would be seen. Also, these studies often may be inadequate to observe the lowest values below which no effects would be observed. Thus these studies have limited statistical power to ascertain the 'threshold' concentration for the health effects from PM exposure. Multiple Epidemiological studies conducted on large population data (Pope et al. 2002, 2009; Dominici et al. 2003) were not able to observe any low concentration threshold for low exposures to PM2.5 exposures and in the absence of any threshold values, suggested that adverse health effects may be observed in populations that are exposed to low PM concentrations. In accordance with the uncertainty stated above, WHO have proposed that regulatory standards that are promulgated cannot lead to 'absolute' protection since the threshold values cannot be ascertained. Thus, the exposure levels cannot be observed as clear-cut definite values and other confounding factors (multi and copollutants, inadequate housekeeping practices, external factors such as dusty roads, construction etc.) need to be considered when assigning health effects from the measured pollutant concentrations.

The standard concentration for PM10 for 24-hour averaging period is $150 \mu \mathrm{g} / \mathrm{m}^{3}$ not to be exceeded once per year averaged over 3 years, and an annual average of $50 \mu \mathrm{g} / \mathrm{m}^{3}$. This annual standard was revoked by EPA effective December 17, 2006 due to lack of evidence linking health problems to long-term PM10 exposure. This standard is still used in other regions, including South America. 


\subsubsection{Regulatory Standards for Gaseous (CO, NOx, $\left.\mathrm{SO}_{2}\right)$ Emissions}

Along with Particulate Matter, the calcining facility may produce mixture of gaseous emissions of $\mathrm{CO}, \mathrm{SO} 2$, and NOx. These gaseous emissions may become a precursor for the formation of acid compounds including nitrates and sulfates (USEPA 2004). Majority of the gaseous pollutants are produced during the thermal processing of the green (raw) coke. The regulatory standards as set up by EPA are presented in Table 4.

\subsection{Petroleum Coke Toxicity}

Though petroleum coke is generally stable, the products from its combustion may be flammable and may produce emissions leading to adverse effects. The combustion of a petroleum coke may may lead to emissions including $\mathrm{CO}, \mathrm{CO} 2, \mathrm{SO} 2, \mathrm{NOx}, \mathrm{PM}$, and heavy metals. The amount of emissions depends upon the type and composition of the green coke (raw material) and the calcined coke (final product). This is shown in Table 1.

Various animal studies and occupational studies have been conducted to identify any adverse health effects from petroleum coke. The toxicity of petroleum coke is dependent upon the type of the constituents of the petroleum coke mixture. The toxicity potential of petroleum coke is different from other mixtures, where individual toxicity can be summed up to calculate final toxicity of the material. But in the case of petroleum coke, the individual components are bound together tightly in the carbonaceous matrix. Thus, the toxicity of individual components in the pure form may not be summed when combined in a petroleum coke matrix, and studies may underestimate or overestimate the risk from the coke exposure. This is shown by various epidemiological studies and animal toxicological studies which have demonstrated low toxicity potential even at higher doses and high toxicity potential even at low doses. 


\subsubsection{Animal Studies}

Animal studies not only help to assign an acute risk but it may also help to ascertain the long term effects of the raw petroleum coke. In addition, high doses may be administered to the animal that is not possible in human trials. Various animal studies have been done to assign a risk to the petroleum coke exposure. Klonne et al. (1987) administered very high doses of green coke to test population of rats and monkeys and measure health effects, including carcinogenicity from exposure to green coke. When exposed to doses of 10.2 and $30.7 \mathrm{mg} / \mathrm{m}^{3}$ for 6 hours/day, 5 hours/week for 2 years, no higher incidence of cancer was observed. Though these levels are about 750,000 times the values observed in petroleum industries and about 6 times higher than the recommended limit, only lung blackening was observed along with mild inflammatory reaction to dust collection in the lungs. Another study done by McKee and White observed no changes in physical properties and mortality rate in earthworms exposed to petcoke mixed with soil at 1:1000. Similarly, the tests done on plant growth (variety of corn, radish and soybean) showed no evidence of stunted growth when these were exposed to petcoke for a period of 21 days. (Mckee et al., 2014). In another study, when species of plants were exposed to pure petcoke and were exposed to real life scenario of exposure due to petcoke dispersal, no changes were observed on germination of seeds but stress symptoms were seen resulting in stunted growth and abnormal physical properties including lowered transpiration (Nakata et al., 2011).

Another study was done with doses ranging from 23 to $199 \mathrm{mg} / \mathrm{m}^{3}$ and test animals were administered for 6 hours/day for 7 days. Exposure to green coke resulted in discoloration of the lung with mild hypertrophy of lung epithelium. Except for the effects mentioned, no other adverse health effects were observed in the test animals from exposure to green or calcined coke (Huntingdon Life Sciences 1999). 
Dermal exposure risk to green and calcined coke has also been studied by Hepler et al. (1982). The mice were exposed to 100 microliters of $25 \%$ solution of green coke on the shaved skin of the animal, 3 times/week for a lifetime. Slight skin thickening along with pigmentation was observed in mice with no increase in skin carcinogenicity. To evaluate the carcinogenicity of the raw petcoke, inhalational studies were done on rats and monkeys (Klonne et al, 1987). When exposed to inhalational doses of 0,10 and $30 \mathrm{mg} / \mathrm{m}^{3}$ for 6 hours/day for 5 days resulted in no excess in carcinogenic rate after 2 years. In another experiment dermal exposure to petcoke for thrice weekly and observed for 2 years resulted in no higher rate of tumor incidence (Hepler et al, 1982). These studies showed that petcoke exposure resulted in no higher carcinogenic rate.

Tests were also conducted to ascertain the reproductive and developmental toxicity of petcoke in animals. Rats were exposed to inhalational micronized petcoke in doses of $0,30,100$, and $300 \mathrm{mg} / \mathrm{m}^{3}$ for 6 hours/day for 2 weeks during periods of mating and gestation. The results showed that no adverse effects were seen in the animal population (Huntingdon Life Sciences, 1999). The newborn also failed to show any developmental adverse effects when parents were exposed to inhaled petcoke. Similar tests were performed with same doses in parent rats and results showed that 3 out of 12 rats failed to conceive and one rat resulted in stillbirth (McKee et al., 2014). In another long term study for 2 years, monkeys and rats were exposed to raw petcoke and observed for 3, 6, 12 and 24 months. The results showed that no effects on body weight and mortality were observed in animal test subjects. Higher neutrophil and leucocytes count with lowering of lymphocytes was observed. These results were irreversible and dependent upon the duration and concentration of the dosage of raw petcoke Though some of the studies showed adverse effects, the majority of research studies concluded that exposure to petcoke does not possess any carcinogenic potential while observing low risk to developmental and reproductive effects. 


\subsubsection{Occupational Studies}

Majority of occupational studies have observed the effect of "petrochemical industries" while there is a lack of studies that have researched the risk of calcined coke on the workers employed in the petroleum industries. The research studies that have been published study the effect of all the pollutant emissions from the facility without regard to effect of individual constituent from the petroleum complex.

Various studies were conducted to observe the lung carcinogenic potential of coking process in cohort studies done in North America (Consantino et al., 1995; Lewis et al., 2003; Sakabe et al., 1975; Wu, 1998; Chau et al 1993; Davies et al 1977; Hurley J.F. 1977). Table 5 shows the relative risk of lung and tracheal carcinoma in workers exposed to raw petcoke during the coking process. Higher risk of lung cancer was observed in worker studies in United States and China with Relative Risk (RR) ratio ranging from 2 to 4.4 but studies from UK, Japan and Netherlands observed lower RR that ranged from 0.8 to 1.4 . Risk of prostatic cancer was highest in workers in studies done in US and Canada whereas no higher risk of carcinogenicity was observed in other countries (Caruso et al., 2015). Though as mentioned above volatile organic compounds are burnt during high temperatures that are employed in the calcining process, the workers employed in the process are still susceptible to gaseous emissions form the process itself. The workers that are employed at the top rather than workers who are employed at the side of the kiln are exposed to higher emissions exposure. 
Table 5 Cohort Studies of Carcinogenic Potential of Coking Process in Workers

\begin{tabular}{|l|l|l|}
\hline Country & No. of worker population & Relative Risk \\
\hline US and Canada & 15,818 & 2.0 \\
\hline Canada & 25,292 & 2.17 \\
\hline Japan & 2178 & 1.3 \\
\hline China & 21,995 & 4.4 \\
\hline France & 536 & 2.5 \\
\hline UK & 610 & 0.8 \\
\hline
\end{tabular}

A study conducted by Divine et al. (1999a, b) observed the mortality from workers employed in the Texaco facility. The workers in the industry were exposed to multiple chemicals, including volatile organic compounds, petroleum coke dust and other heavy metals. The study subjects were refinery workers employed in the facility from 1947 till 1993 and increased cancer incidence was observed. The study showed that Standardized Mortality Ratios were slightly higher for workers in coking unit as compared to other workers though the result was not statistically significant. In addition, no statistically significant results were observed in the workers employed in delayed coking units or in those who were employed in coking units for more than 5 years.

Another study was done by Lipscomb and Lee (1983) of the workers employed in a petroleum coke facility in Port Arthur, Texas. 90 employees were recruited for spirometry and chest X-rays. Questionnaires were given to workers to report incidences of health effects. The results were compared with the area and personal samples of PM, silica dust and PAH's. The average PM concentration and respirable dust concentration was $3.4 \mathrm{mg} / \mathrm{m}^{3}$ and $0.44 \mathrm{mg} / \mathrm{m}^{3}$, respectively. Nine employees had abnormal spirometry function tests with 5 questionnaire reporting chronic bronchitis. The cancer deaths that were observed in the workers were not statistically significant. Though the 
study reported abnormal lung function tests, no control group was selected to compare observed lung effects in the unexposed population.

Though cigarette smoking is most commonly associated with certain lung diseases such as COPD, occupational exposures have been attributed in about 20 percent of the cases. One study observed the incidence of COPD in workers employed in the coking process. The results showed 5.8 percent increase in risk of COPD in workers who were employed in the coking process $(\mathrm{Hu}, \mathrm{Y}$. et al., 2006). In another large cohort study done in United States, the incidence of non- malignant lung condition was observed. The study observed 2.2 times higher risk of lung conditions in workers in coke oven factories (Redmond C.K., 1983).

\subsection{Risk Assessed in Epidemiological Studies from Petrochemical Industries}

Various studies have observed the effect of PM emitted from petrochemical industries on human health. These studies have included both acute as well as chronic effects on respiratory and cardiovascular health of the exposed populations. The studies have assessed the role of PM and gaseous pollutants from combustion and mobile sources in producing cardiovascular and respiratory health effects. Mortality studies have assessed the number of deaths occurring for particular time periods and the exposure levels during those periods. Morbidity studies have involved the study of hospital admission rates, symptoms, disease, levels of lung functions or restricted activity.

\subsubsection{Petrochemical Industry and Pollutant Emissions}

The pollutant emissions (PM, VOC's or gaseous content) in an industrial area is not a function of presence or absence of the facility but is dependent upon various other factors including contribution by anthropogenic sources, effectiveness of control factors maintained by the facility etc. Various studies have examined the association of petrochemical industries in the residential 
areas and the health effects in the respective population, including children. (Rovira et al., 2014; Mukesh et al., 2004; White et al., 2009; Smargiassi et al., 2009; Wichmann et al., 2009; Brunekreef B.et al., 1995; Gauderman et al., 2005).

Rovira et al. (2014) studied the effect of oil refinery emissions on the asthma symptoms and lung function in children residing near the petrochemical areas. The study showed that the population residing in the petrochemical areas had more episodes of respiratory symptoms (cough) and higher hospitalization rate as compared to the control population but no higher symptoms of asthma was noted. Mukesh et al. (2004) observed the effect of PM10 and PM2.5 levels on the levels of FEV1 and FVC in Kanpur, India. The study measured the lung functions from three different locations with varied exposure to PM. The PM concentration in these areas ranged from 184 to $295 \mu \mathrm{g} / \mathrm{m}^{3}$. The study showed that subjects in areas of higher exposure had more reduction in Peak Exploratory Flow Rate (PEFR) per unit increase in PM10. Gauderman et al. (2005) studied the effect of ambient air pollution on the growth of lung function and change in FEV1 among age groups of 10-18 years for a period of eight years. The study stated that exposure to ambient air pollution led to significant deficits in FEV1 in study population. Another study showed that with increase in air pollution levels, the prevalence of respiratory symptoms increased significantly in respiratory compromised patients though no such significance was found in the population without PEF variability (Boezen, 1998).

Wichmann et al. (2009) observed morbidity indicators namely asthma rates, asthma exacerbations, respiratory disease symptoms and decrease in lung function in residents surrounded by the petroleum complex. The study found a positive association between ambient air pollution and decrease in respiratory health. Some studies though have related the association between pollutants and negative effects on lung functions, these do not describe to what extent exposed and unexposed are in contact with the air pollutant. Smargiassi et al. (2009) studied the effect SO2 from point 
sources on asthma hospitalizations near petroleum refineries in Montreal, Canada. Though the study pointed out the short term exposure to $\mathrm{SO} 2$ led to higher rates of asthma hospitalization, the exposure group (children aged 2-4) did not represent the exposed groups in the study. The study is performed on the children who are presumed to be 'exposed' to the ambient air pollution. The very observation that the exposed group spent most of their time inside homes, it does not represent an actual exposure group which undermines the association derived in the study. White et al. (2009) studied the effect of vicinity to petrochemical refinery and the development of asthma symptoms. The study found that prevalence of asthma symptoms was higher in the children due to presence of the petroleum refinery in the area. In the study the groups of 'disease' and 'non disease' are framed on the questionnaire obtained from students. Such procedure of 'measuring' disease is not representative

of the actual exposure and outcome and can under or over-estimates the outcome being measured. When the studies especially the cross sectional studies observe the association of one-time measurement of air pollution level with adverse health effects, they may be inadequate to quantify the levels of air pollutant associated with the health effects or quantify the threshold levels of PM which would result in changes in lung function.

\subsubsection{Single Pollutant and Multiple Pollutant Exposures}

Ambient air pollution is due to conglomerate of multiple sources and pollutants. In the studies which have one pollutant models, the association may be of significance since they do not interact and act an independent risk factor but most of the pollutants do not act independently for the outcome and may have a correlation (positive or negative) with other pollutants. Atkinson et al. (1999) noted that in one-pollutant models $\mathrm{PM} 10, \mathrm{NO}_{2}$ and $\mathrm{SO}_{2}$ were significantly associated with increase in asthma cases but when the pollutants were studied in a multi pollutant model i.e. when 
the pollutants were added to another pollutant, statistical significance decreased thereby suggesting these pollutants may not act independently in the ambient atmosphere.

Some studies have tried to measure the individual effects of the air pollutants and their association with health effects. It is difficult to separate the health effects of the air pollutant individually because of correlation. This was observed by Ilabaca et al. (1999) study while observing the effects of the particulate fine particles on the respiratory health of children. The impact of the pollutant then cannot be observed in seclusion but the admission that multiple pollutants may act as confounders, is required while deriving outcomes of health effects.

The epidemiological studies have assessed the role of acute exposure, and have related small time changes in exposure to the acute adverse effects. Maestrelli et al. (2001) showed that increase in PM10 concentrations was associated with increase in SGRQ and ACT scores in asthmatic patients. In addition, the presence of the facility by itself is not a risk factor for the occurrence of health effects observed in the population but it is dependent upon the amount of air ambient pollutants. It is important to recognize sources of those pollutants since it would help the regulatory agencies to localize the source and control the emissions. Loyo-Berríos, N.I. et al. (2006) noted that asthma cases living near the air pollution sources showed higher risk of asthma attacks, the odds ratio ranged from 1.28 and 1.44 for the asthmatic cases as compared to non-asthmatic controls. In the study, exposure group (cases) were asthmatic children whose asthma exacerbations were attributed to air pollution sources but no information was provided on the specific sources of pollution. Wichmann et al. (2009) specifically studied the role of PM and volatile organic compounds (VOC) in region of La Plata, Argentina. The study measured PM10 and VOC in the area for 4-week period in winter months of 2005 and 2006. The study found that children living near the petrochemical industrial areas had higher asthma rates and asthma exacerbations with lowered FEV1 
than in the non-industrial areas. The study measured the total PM10 concentrations from all sources without individual contributions of the petroleum, industrial and human activity sources.

Jedrychowski et al. (1999) study in Poland found lowered lung growth and decrease in FEV1 values in preadolescent children exposed to ambient air pollutants. Along with studying the outdoor pollution from sources such as traffic, indoor air pollutants were also studied including social factors such as gas fumes and tobacco smoke. The study showed higher proportion of test subjects which were exposed to outdoor and indoor air pollution had slower lung function growth.

Epidemiological studies have observed an exposure response characterization that may demonstrates higher morbidity rates at levels below current regulatory standards or an exposure response that can be used to inform risk assessment (Frye et al., 2003; Peng et al, 2009; Dominici et al., 2006). In addition, most of the epidemiological studies that measure the ambient surrounding attempt to recognize the importance of outdoor and indoor air quality in calculating the actual exposure. The risk assessment from these studies is dependent upon the average concentrations from multiple monitors installed at varied places. Such risk assessment studies may lead to under or overestimation of air pollution adverse effects. Also, it is difficult to assign the exposure to subjects who are divided into cases and controls in various epidemiological studies including the studies that utilize hospital admission rates as an outcome of ambient air pollution effect. Frye et al. (2003) observed the effect of air pollutants (Total Suspended Particles, $\mathrm{SO}_{2}$ ) on the school children residing in East Germany. The study subjects were school children from $6^{\text {th }}$ grade and cross sectional surveys were undertaken from 1992- 1999. Annual mean concentration of TSP and $\mathrm{SO}_{2}$ were collected from monitors at 3 sites. Along with the respiratory tests, questionnaires were completed by parents recording adverse respiratory signs or symptoms. The study showed that decrease in air pollutant levels resulted in an improvement in lung function tests with lowering of FVC that was statistically 
significant. No statistical significance was observed with effects on FEV1. Dominici et al. (2006) calculated the hospital admission rates associated with PM2.5 and found a positive association for respiratory diseases. The hospital admission rates measured by Dominici study though have estimated an association but such studies are confounded by multiple factors (publication bias, regional variability and misclassification of disease) and may not be adequate in assigning individual health exposures and risks. Also, it is debated as to what extent does exposure data represent the actual exposure to measure the outcome (changes in lung function, asthma exacerbations etc.) and how well does they represent the differences in the study population (cases or controls, exposed or non-exposed). Also, with inadequate assessment of the exposure, epidemiological studies vary on the methods on which the study populations are selected (depending upon the exposure), which may confound the association between exposure and the outcome.

\subsubsection{Petrochemical Industries and Study Protocols}

Studies have often utilized questionnaires and other similar approaches (health insurance claims) to associate lung function tests and exposure to petrochemicals industries (Ware et al., 1993; Yang et al., 1998; Loyo-Berríos et al., 2007; Moraes et al., 2010; Rusconi et al., 2011). Ware J.H. et al. (1993) used questionnaire to study the incidence of respiratory symptoms in children residing in areas surrounded by petrochemical industries. The exposure was calculated for collective petroleum compounds specific to the industry. The study showed that higher emissions were associated with increased rates of respiratory symptoms. Yang et al. (1998) and Rusconi et al. (2011) compared the symptoms in children residing in areas surrounding petrochemical industries with children living in areas without petrochemical complex. The incidence was measured by questionnaire answered by the parents. The results showed that children living in areas with petrochemical complex had higher rates of respiratory symptoms. In another study done by Loyo-Berríos et al. (2007), health insurance 
and medical insurance claims were compared with the population residing in the areas with petrochemical industries and showed that people living near petrochemical areas had higher incidence of asthma attacks.

Epidemiological data from air pollution studies are plagued by unknown confounders while measuring exposures that skew the results of statistical analysis. When the epidemiological studies evaluate the effect of one-time measurement of air pollution levels, the data may be inadequate to quantify the amount of air pollutants which are associated with the health effects or levels which would result in change in lung functions. These studies, though have observed an association between pollutants and negative effects on lung functions, do not adequately describe to what extent 'exposed' and 'unexposed' population are in contact with the pollutant. 


\section{CHAPTER THREE:}

\section{METHODOLOGY}

\subsection{Calcining Facility-Copetro}

This research study was conducted to examine the risk associated with a calcining facility in a residential area and further evaluate the role of this facility on total pollutant load in the environment. Copetro plant is located within the port of La Plata in eastern Argentina and is surrounded by the residential communities of Ensenada and Berisso on west and southeast, respectively. The long and narrow property containing the facility abuts west side of the shipping canal and has a south-southwest to north-northeast orientation. From a turning basin at its southsouthwestern terminus, the shipping canal extends north-northeast to the city of Rio de la Plata (Figure 5).

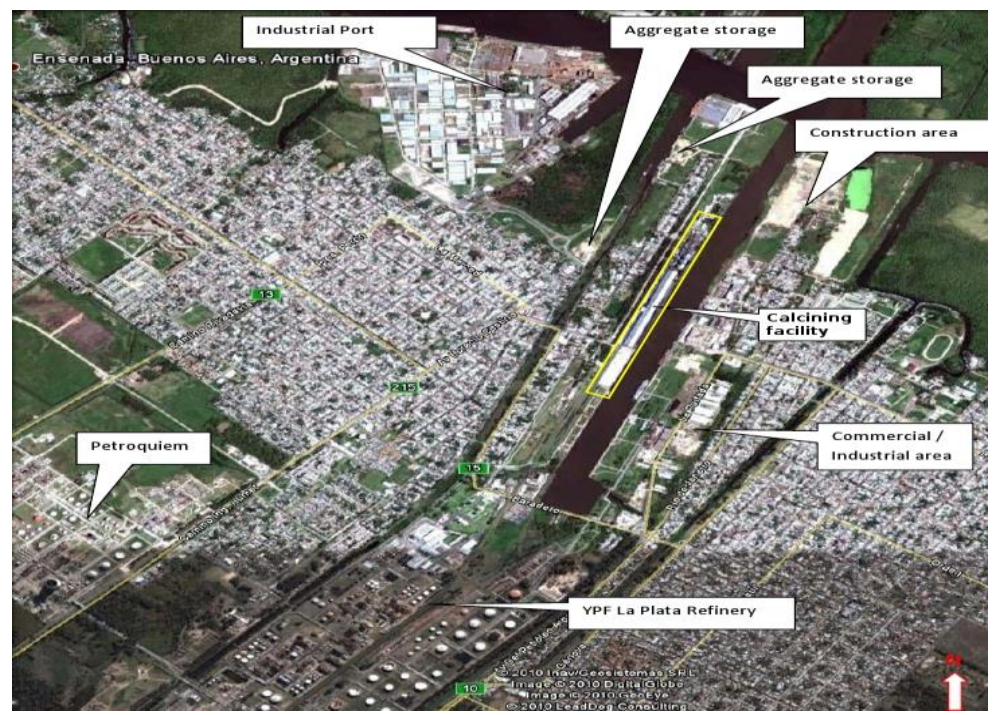

Figure 5 Copetro Calcining Facility Complex 
The facility produces about 444,000 short tons per year of calcined coke. The area also has an oil refinery that supplies green petroleum coke, Petroquiem (oil refinery), industrial ports and areas, with large population communities surrounding the facilities. We considered the meteorological data while evaluating the emissions of this facility. The general direction of the air flowing over the weather station located in the calcining facility is towards urban areas, and it first passes over the River Plate (influenced by its interaction with the water) and then, over a narrow surface on the shore, between the river and the weather station. The air towards the monitors flows first over the urban areas surrounding the facility. As mentioned previously in the paragraph, there is an oil refinery proximate to the area where the calciner resides and hence there are multiple sources of pollution in the area including the refinery, sand and gravel storage and transport, and other industrial activities.

\subsection{Measurement of Pollutants}

The emission constituents that were evaluated included PM10 and gaseous emissions of CO, $\mathrm{SO}_{2}$, and $\mathrm{NO}_{x}$. Volatile Organic Compounds (VOC) were not recorded from the facility since the petroleum plant does not produce any semi-volatile organic compounds from the kiln stacks or from the raw petroleum coke. These semi-volatile compounds are efficiently combusted and destroyed during the calcining process. High temperatures from the gas burners lead to the combustion of the vaporized materials from the raw coke into an amorphous form.

Both measured and modeled emissions from the kiln stacks, as well as actual ambient air

monitoring was conducted for the above mentioned pollutants. Ambient air quality PM10 monitoring data was collected continuously by three tapered element oscillating microbalance (TEOM 1400) monitors, and one multi-angle absorption photometer (MAAP) monitor at various 
locations surrounding the facility. Air data collection for year 2009 was conducted by the Center for Environmental Investigations (CIMA by its Spanish acronym). For the period of 2010 through the second quarter of 2013, air data was collected by the facility under the direct supervision of The Provincial Agency for Sustainable Development (which acts as the regulatory agency and is known as OPDS by its Spanish acronym). For the third quarter of 2013 through second quarter of 2014, air data was collected by the Geochronology and Isotopic Institute (INGEIS by its Spanish acronym).

As part of the data collection activities, CIMA utilized three TEOM 1400 monitors, two HI-Vol PM10 monitors, and a MAAP monitor to measure the ambient air quality at various locations surrounding the calcining facility. The TEOM 1400s and MAAP monitors were used for PM10 monitoring by the calcining facility at various locations from 2010 through the first half of 2013. INGEIS continued to use the same monitors at various locations around the facility for the second half of 2013 till the present date. The locations and distance of these monitors have varied over time with the nearest location just at the entrance of the facility and the furthest at 1,190 meters from the calcining facility. TEOM monitors measure continuous ambient air quality values, while Hi-Vol samplers are based on 24-hour samples that are typically taken on 3 or 6 day intervals.

Periodic stack testing was also done by the Calcining facility to monitor $\mathrm{PM}, \mathrm{NO}_{\mathrm{x}}, \mathrm{CO}$ and $\mathrm{SO}_{2}$ emission rates from the two ovens from 2011 through the third quarter of 2014. The kiln stack samples were collected using the EPA Conditional Test Method (CTM) 022/030. The rates of pollutant emissions were then input into an air dispersion model along with 5 years of meteorological data. The EPA's AERMOD model (Version 07026) was used with hourly meteorological data to predict PM emission impacts at ground-level receptor locations for 24-hour averaging periods. AERMOD is a Gaussian plume model that calculates impacts at each receptor 
for each hour in the meteorological data set (typically a full year of data) and it provides maximum ground-level concentrations for point sources such as the two Kiln stacks. It also predicts concentrations in the cavity zone and uses Building Profile Input Program (BPIP) data to simulate the influence of proximate structures to estimate the downwash effects. The results of the modeling were compared to the ambient air quality sampling efforts discussed above as well as local and USEPA ambient air quality standards. (EPA, 2004). The gaseous pollutants were modeled using AERMOD model to calculate 3-hour and 1-hour concentrations. 1-hour concentrations were compared with the USEPA and Argentina standards.

The measured and modeled particulate levels in ambient air from the calciner facility were compared to standards protective of public health risk. For the year 2009, in addition to comparison with the USEPA regulatory standards, variable analysis by calculating minimum, maximum, and median values of the 24- hour PM10 concentrations was done. Similarly, for Year 2009 till third quarter of 2014, quarterly analysis by calculating minimum, maximum and average of monthly PM10 at monitors TEOM 3, 4 and 5 was done. Tabular analysis of PM10 values was also done that were higher than the regulatory standards of $150 \mu \mathrm{g} / \mathrm{m}^{3}$ at all three TEOM locations.

\subsection{Analysis of Epidemiological Risk Assessment Studies}

The epidemiological studies examining the pollutant levels help in understanding pollutant exposure levels that may be expected to produce adverse health effects or demonstrate the levels at which higher risk may be expected. Majority of the epidemiological studies have examined the ambient PM and its association with acute respiratory effects including asthma, exacerbation of asthma symptoms, increase or decrease in medication use, hospital or emergency ward admissions. Epidemiological studies that have attempted to evaluate the effect of multiple pollutants, the correlation among these pollutants may change the power of association than when measured for 
individual pollutants. Further, the air pollution studies are plagued by the presence of unknown confounders that may tend to skew the results of statistical analysis. Therefore, there is no one correct approach to assess the exposure levels of the individual pollutants that can appropriately assess the exposure-outcome association.

We evaluated the epidemiological studies exploring the exposure levels of the modeled $\mathrm{SO}_{2}$, $\mathrm{CO}, \mathrm{NO}_{\mathrm{x}}$ and PM10 concentrations from the calcining facility and assessed whether these levels fall below the public health air quality standards. The risk assessment of the ambient air emissions would depend upon a meaningful study population selection and clear diagnostic criteria which would have the analytic power in obtaining reliable exposure measurements. Thus, we carefully reviewed the epidemiological studies to assess if the levels that assign risk in these studies adequately correlate with the standards that are promulgated to protect public from adverse health effects from the petrochemical emissions. Inclusion criteria for the epidemiological study review included studies where the exposure was directly from the petrochemical industry and where risk was assessed in terms of adverse respiratory health effects (asthma incidence, asthma exacerbations, changes in lung function levels, other respiratory symptoms, lung cancer or mortality from lung cancer etc.). Informal PubMed search was conducted using terms: oil refinery, petrochemical industry, calcining, and petroleum coke workers with no filters for publication year. Additional studies were selected from the identified research studies references. Studies published in peer-reviewed journals and in English language only were included 


\section{CHAPTER FOUR:}

RESULTS

\subsection{Particulate Matter Emissions from the Calcining Facility}

The PM10 concentration contributed by the Copetro facility was measured according to the wind speed and wind direction of the emissions from the facility. If the wind direction was in the way of the Copetro facility, such that the wind traversed the monitors, then the relative PM pollution was measured from the facility's kiln, silos, loading-unloading of raw coke, and conveyor belts. If the wind did not traverse through the facility site location, then the facility contribution to the total PM concentration was assumed to be minimal.

Table 624 -Hour PM10 levels for year 2008

\begin{tabular}{|c|c|c|c|c|c|c|c|}
\hline Location & Date & Total & $\begin{array}{l}\text { Petrochemical } \\
\text { industry wind } \\
\text { contribution* }\end{array}$ & Location & Date & Total & $\begin{array}{l}\text { Petrochemical } \\
\text { industry wind } \\
\text { contribution* }\end{array}$ \\
\hline \multirow{5}{*}{$\begin{array}{l}\text { Francia } \\
\text { y } \\
\text { Almafuerte }\end{array}$} & $6 / 13 / 2008$ & 58.4 & $<1$ & \multirow{5}{*}{ Entre Rios } & $10 / 6 / 2008$ & 81.5 & 14.6 \\
\hline & $6 / 7 / 2008$ & 54.5 & 31 & & $6 / 14 / 2008$ & 73.6 & - \\
\hline & $6 / 14 / 2008$ & 48.6 & $<1$ & & $11 / 26 / 2008$ & 70.3 & - \\
\hline & $5 / 31 / 2008$ & 48.6 & 15 & & $10 / 22 / 2008$ & 61.2 & 41 \\
\hline & $7 / 14 / 2008$ & 45.2 & 43 & & $11 / 27 / 2008$ & 59.3 & 16 \\
\hline & & & & & & & \\
\hline \multirow{5}{*}{ San Luis } & $10 / 6 / 2008$ & 87.7 & 15 & \multirow{5}{*}{ Santa Fe } & $11 / 6 / 2008$ & 119.6 & 89.2 \\
\hline & $10 / 11 / 2008$ & 59.6 & - & & $11 / 7 / 2008$ & 107 & 63.7 \\
\hline & $10 / 5 / 2008$ & 55 & 3 & & $11 / 8 / 2008$ & 99.2 & 61.2 \\
\hline & $10 / 9 / 2008$ & 54.7 & 0 & & $11 / 26 / 2008$ & 93.1 & 69.7 \\
\hline & $10 / 10 / 2008$ & 43.4 & 0 & & & & \\
\hline
\end{tabular}

* Concentration in $\mu \mathrm{g} / \mathrm{m}^{3}$ 
The levels of PM10 for the year 2008 were monitored at four different locations, Entre Rios, Francia y Almafuerte, San Luis, and Sante Fe as shown in Table 6. The table shows that at the Entre Rios, Copetro contribution was about $18 \%\left(14.6 \mu \mathrm{g} / \mathrm{m}^{3}\right)$ to the highest PM10 concentration recorded at the site $\left(81.5 \mu \mathrm{g} / \mathrm{m}^{3}\right)$. For the $2^{\text {nd }}$ highest PM10 concentration $\left(73.6 \mu \mathrm{g} / \mathrm{m}^{3}\right)$, Copetro contribution, in accordance to the wind direction, was negligible with less than $1 \mu \mathrm{g} / \mathrm{m}^{3}$. At Francia y Almafuerte and San Luis, Copetro contribution was $43 \mu \mathrm{g} / \mathrm{m}^{3}$ and $15 \mu \mathrm{g} / \mathrm{m}^{3}$ respectively, with respect to the highest PM10 concentrations recorded in the area. At Santa Fe, the highest PM contribution was $119.6 \mu \mathrm{g} / \mathrm{m}^{3}$ with Copetro contributing about $75 \%$ of the emissions.

Table 7 24-Hour PM10 Concentrations Measured by Hi-Vol and TEOM in 2009

\begin{tabular}{|c|c|c|c|c|c|}
\hline & Date & $\begin{array}{l}\text { Hi-Vol } \\
\left(\mu \mathrm{g} / \mathrm{m}^{3}\right)\end{array}$ & $\begin{array}{l}\text { TEOM } \\
\left(\mu \mathrm{g} / \mathrm{m}^{3}\right)\end{array}$ & $\begin{array}{c}\text { Calcining Facility } \\
\text { Contribution } \\
(\%)\end{array}$ & $\begin{array}{c}\text { Non-Calcining } \\
\text { Facility Contribution } \\
(\%)\end{array}$ \\
\hline \multirow{10}{*}{$\begin{array}{l}\text { Monitor } \\
\mathbf{1 6 4} \mathbf{~ m} \\
\text { from } \\
\text { facility } \\
\text { (Site A) }\end{array}$} & $6 / 1 / 2009$ & 219 & 92 & 38 & 62 \\
\hline & $12 / 1 / 2009$ & 124 & 79 & 75 & 25 \\
\hline & $18 / 01 / 2009$ & 115 & 56 & 98 & 2 \\
\hline & $24 / 01 / 2009$ & 145 & 88 & 48 & 52 \\
\hline & $30 / 01 / 2009$ & 19 & 30 & 64 & 36 \\
\hline & $5 / 2 / 2009$ & 50 & 39 & 4 & 96 \\
\hline & $11 / 2 / 2009$ & 55 & 62 & 70 & 30 \\
\hline & $18 / 02 / 2009$ & 48 & 53 & 57 & 43 \\
\hline & $24 / 02 / 2009$ & 65 & 51 & 43 & 57 \\
\hline & Date & $\begin{array}{l}\text { Hi-Vol } \\
\left(\mu \mathrm{g} / \mathrm{m}^{3}\right)\end{array}$ & $\begin{array}{l}\text { TEOM } \\
\left(\mu \mathrm{g} / \mathrm{m}^{3}\right)\end{array}$ & $\begin{array}{c}\text { Calcining Facility } \\
\text { Contribution } \\
(\%)\end{array}$ & $\begin{array}{c}\text { Non-Calcining } \\
\text { Facility Contribution } \\
(\%)\end{array}$ \\
\hline \multirow{9}{*}{$\begin{array}{l}\text { Monitor } \\
\mathbf{4 8 5} \mathrm{m} \\
\text { from } \\
\text { facility } \\
\text { (Site B) }\end{array}$} & $6 / 1 / 2009$ & 167 & 75 & 49 & 51 \\
\hline & $12 / 1 / 2009$ & 122 & 49 & 33 & 67 \\
\hline & $18 / 01 / 2009$ & 71 & 38 & 94 & 6 \\
\hline & $24 / 01 / 2009$ & 94 & 46 & 23 & 77 \\
\hline & $30 / 01 / 2009$ & 24 & 25 & 46 & 54 \\
\hline & $5 / 2 / 2009$ & 46 & 30 & 3 & 97 \\
\hline & $11 / 2 / 2009$ & 56 & 42 & 70 & 30 \\
\hline & $18 / 02 / 2009$ & 24 & 24 & 13 & 87 \\
\hline & $24 / 02 / 2009$ & 42 & 34 & 29 & 71 \\
\hline
\end{tabular}

Table 7 shows the measured 24-hour ambient air quality concentrations for PM10 of Hi-Vol and TEOM samplers for the year 2009. The monitors (Hi-Vol and TEOM) were located at 164 meters 
and 485 meters from the facility. Table 8 analyzes the concentrations of PM10 from Hi-Vol and TEOM samplers as measured in Table 7 and shows that highest concentration of $219 \mu \mathrm{g} / \mathrm{m}^{3}$ was recorded by Hi-Vol monitors while the highest concentration recorded by TEOM monitors was 92 $\mu \mathrm{g} / \mathrm{m}^{3}$. Similarly, for monitors installed at the distance of $485 \mathrm{~m}$ recorded highest concentration of $167 \mu \mathrm{g} / \mathrm{m}^{3}$ at $\mathrm{Hi}-\mathrm{Vol}$ monitors and $75 \mu \mathrm{g} / \mathrm{m}^{3}$ at TEOM monitors.

Table 8 Analyses of 24-Hour PM10 Concentrations in 2009

\begin{tabular}{|c|c|c|c|c|c|}
\hline Site A & $\begin{array}{l}\text { Hi-Vol } \\
\left(\mu \mathrm{g} / \mathrm{m}^{3}\right)\end{array}$ & $\begin{array}{l}\text { TEOM } \\
\left(\mu \mathrm{g} / \mathbf{m}^{3}\right)\end{array}$ & Site B & $\begin{array}{l}\text { Hi-Vol } \\
\mu \mathrm{g} / \mathrm{m}^{3}\end{array}$ & $\begin{array}{l}\text { TEOM } \\
\mu \mathrm{g} / \mathrm{m}^{3}\end{array}$ \\
\hline Min & 19 & 30 & Min & 24 & 24 \\
\hline Max & 219 & 92 & Max & 167 & 75 \\
\hline Median & 65 & 56 & Median & 56 & 38 \\
\hline Half of Max & 109.5 & 46 & Half of Max & 83.5 & 37.5 \\
\hline Sqrt & 14.8 & 9.5 & Sqrt & 12.9 & 8.7 \\
\hline
\end{tabular}

Table 9 and figure 6 shows the PM10 concentrations as measured from 2009 through the 3rd quarter of 2014 at TEOM 3 location. This monitor is located at the La Paz, Ensenada location which is about 889 meters from the calcining facility. 
Table 9 Monthly 24-hour Average of PM10 for TEOM 3 for Time Period-1st Quarter 2009 Through 3rd Quarter 2014

\begin{tabular}{|c|c|c|c|c|c|}
\hline \multicolumn{2}{|c|}{ Period } & \multicolumn{4}{|c|}{ TEOM 3} \\
\hline Year & Quarter & Avg. & Min & Max & 75th \\
\hline & 1st & 28.9 & 2.4 & 103.6 & 35.3 \\
\hline & 2nd & 37.6 & 6.3 & 177.2 & 45.7 \\
\hline \multirow[t]{4}{*}{2009} & 3rd & 26.3 & 7.8 & 124.3 & 30.2 \\
\hline & 4th & 23.8 & 7.6 & 68.3 & 26.6 \\
\hline & 1st & 23 & 7.6 & 57.4 & 29 \\
\hline & 2nd & 26.1 & 6.1 & 80 & 32.1 \\
\hline \multirow[t]{4}{*}{2010} & 3rd & 28.5 & 3.5 & 92.7 & 33.2 \\
\hline & 4th & 27.7 & 11.7 & 86.9 & 31.6 \\
\hline & 1 st & 23.9 & 11.4 & 53.2 & 27.5 \\
\hline & 2nd & 39.9 & 9.2 & 210.3 & 50.2 \\
\hline \multirow[t]{4}{*}{2011} & 3rd & 38.9 & 9.4 & 133.6 & 60.3 \\
\hline & 4th & 28.2 & 12.1 & 53.4 & 34.6 \\
\hline & 1st & 26.6 & 10.1 & 65.8 & 31.1 \\
\hline & 2nd & 30.7 & 6.8 & 70.6 & 38 \\
\hline \multirow[t]{4}{*}{2012} & 3rd & 25.5 & 5.4 & 61.1 & 27.4 \\
\hline & 4th & 25 & 6.8 & 88.8 & 29.8 \\
\hline & 1st & 21.5 & 5 & 50.8 & 24.9 \\
\hline & 2nd & 28.3 & 7.3 & 65.8 & 34.5 \\
\hline \multirow[t]{4}{*}{2013} & 3rd & 26.2 & 8.6 & 79 & 36 \\
\hline & 4th & 25.5 & 8.2 & 58.1 & 31.4 \\
\hline & 1 st & 20.2 & 6.5 & 48.3 & 24 \\
\hline & 2nd & 29.1 & 10.5 & 71.9 & 37.1 \\
\hline 2014 & 3rd & 29.9 & 13.2 & 105.4 & 34.1 \\
\hline
\end{tabular}

The observations were done every five minutes per monitor, thus averaging 288 observations for 24- hour period. The maximum 24-hour average PM10 concentration was $210.3 \mu \mathrm{g} / \mathrm{m}^{3}$ in year 2011 while the average concentration for each quarter ranged from $23.0-39.9 \mu \mathrm{g} / \mathrm{m}^{3}$. 


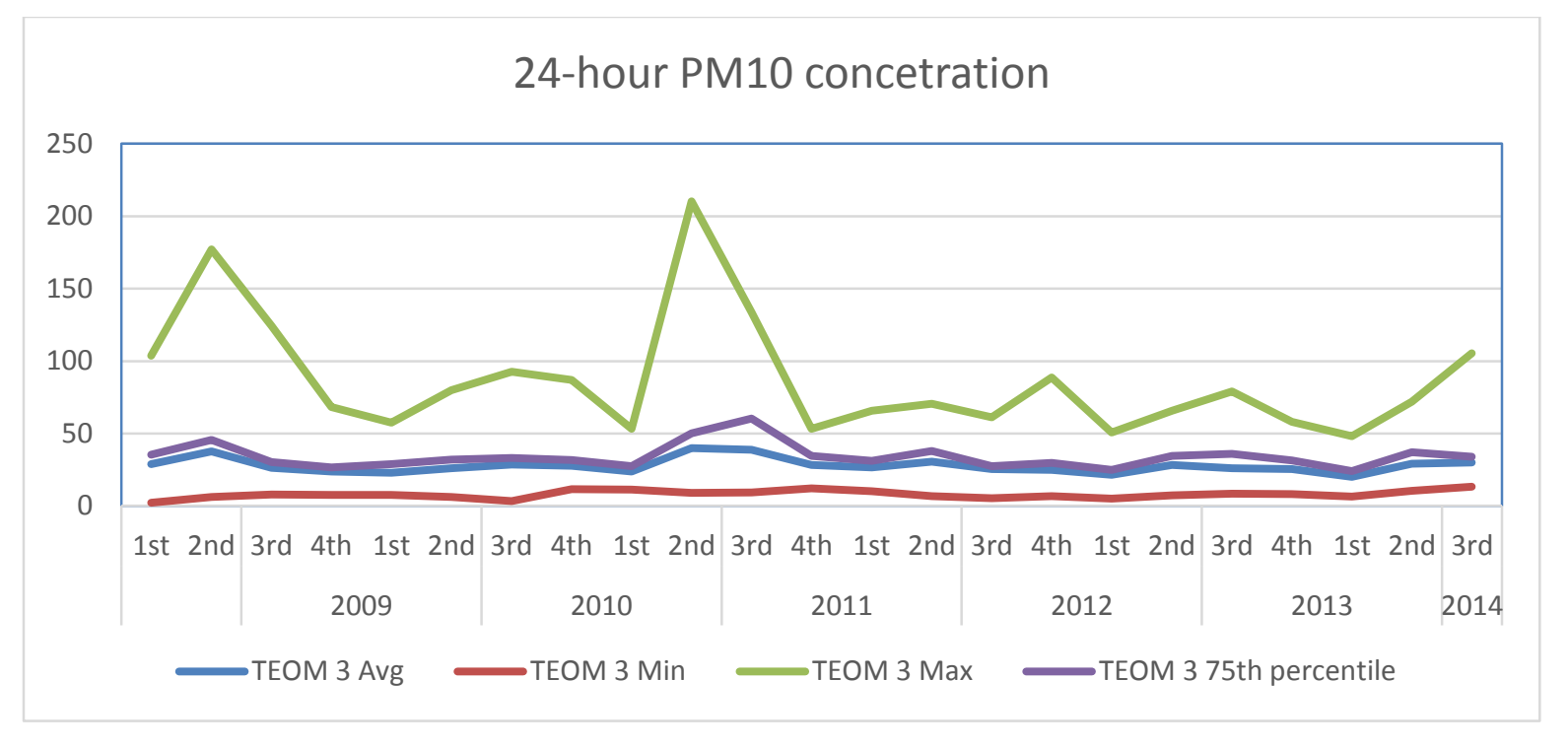

Figure 6 24-hour PM10 Average for TEOM 3 monitor

Table 10 and figure 7 shows the PM10 concentrations as measured from 2009 through the 3rd quarter of 2014 at TEOM 4 location. This monitor is located at the Puerto Puesto, Berisso location which is about 813 meters from the calcining facility. The observations were done every five minutes per monitor thus averaging 288 observations for 24- hour period. The maximum 24hour average PM10 concentration was $195.1 \mu \mathrm{g} / \mathrm{m}^{3}$ in year 2011 while the average concentration for each quarter ranged from $15.5-54.0 \mu \mathrm{g} / \mathrm{m}^{3}$.

Table 10 Monthly 24-hour Average of PM10 for TEOM 4 for Time Period-1st Quarter 2009 Through 3rd Quarter 2014

\begin{tabular}{|c|c|c|c|c|c|}
\hline \multirow{3}{*}{ Year } & & \multicolumn{4}{|c|}{ TEOM 4 } \\
\cline { 2 - 6 } & Quarter & Avg & Min & Max & 75th \\
\hline \multirow{4}{*}{2009} & 1st & 37.5 & 12.2 & 88.4 & 42.7 \\
\cline { 2 - 6 } & 2nd & 36.3 & 6.5 & 168.2 & 39.3 \\
\cline { 2 - 6 } & 3rd & 36.2 & 5 & 101.4 & 43.7 \\
\hline \multirow{3}{*}{$\mathbf{2 0 1 0}$} & 4th & 34.2 & 12.8 & 63.5 & 37.6 \\
\cline { 2 - 6 } & 1st & 41.5 & 12.7 & 115.1 & 51.7 \\
\cline { 2 - 6 } & 2nd & 54 & 8.2 & 139.9 & 72.7 \\
\cline { 2 - 6 } & 3rd & 40.1 & 5.3 & 158.1 & 49.7 \\
\hline
\end{tabular}


Table 10 (Continued)

\begin{tabular}{|c|c|c|c|c|c|}
\hline \multirow[b]{2}{*}{ Year } & \multicolumn{5}{|c|}{ TEOM 4} \\
\hline & Quarter & Avg & Min & Max & 75th \\
\hline \multirow{4}{*}{2011} & 1st & 39.4 & 6.1 & 102.8 & 48 \\
\hline & 2nd & 56.5 & 11.6 & 195.1 & 76.1 \\
\hline & 3rd & 46.7 & 10.5 & 156.5 & 57.6 \\
\hline & 4th & 28.3 & 6.7 & 155.1 & 36.7 \\
\hline \multirow{4}{*}{2012} & 1st & 24.9 & 10 & 70 & 28.5 \\
\hline & 2nd & 22.5 & 5.2 & 81 & 27.5 \\
\hline & 3rd & 33 & 6.9 & 164.5 & 33.4 \\
\hline & 4th & 33.2 & 5.5 & 122.2 & 45.2 \\
\hline \multirow{4}{*}{2013} & 1st & 30.8 & 8.1 & 61.2 & 40.6 \\
\hline & 2nd & 24.9 & 6.7 & 81.7 & 29.3 \\
\hline & 3rd & 27.8 & 3.9 & 90 & 40.7 \\
\hline & 4th & 28.2 & 5.5 & 182.9 & 32.2 \\
\hline \multirow{3}{*}{2014} & 1st & 20 & 6.2 & 75.3 & 24.8 \\
\hline & 2nd & 15.5 & 2.2 & 44.4 & 19.2 \\
\hline & 3rd & 15.8 & 7.1 & 44.5 & 18.4 \\
\hline
\end{tabular}

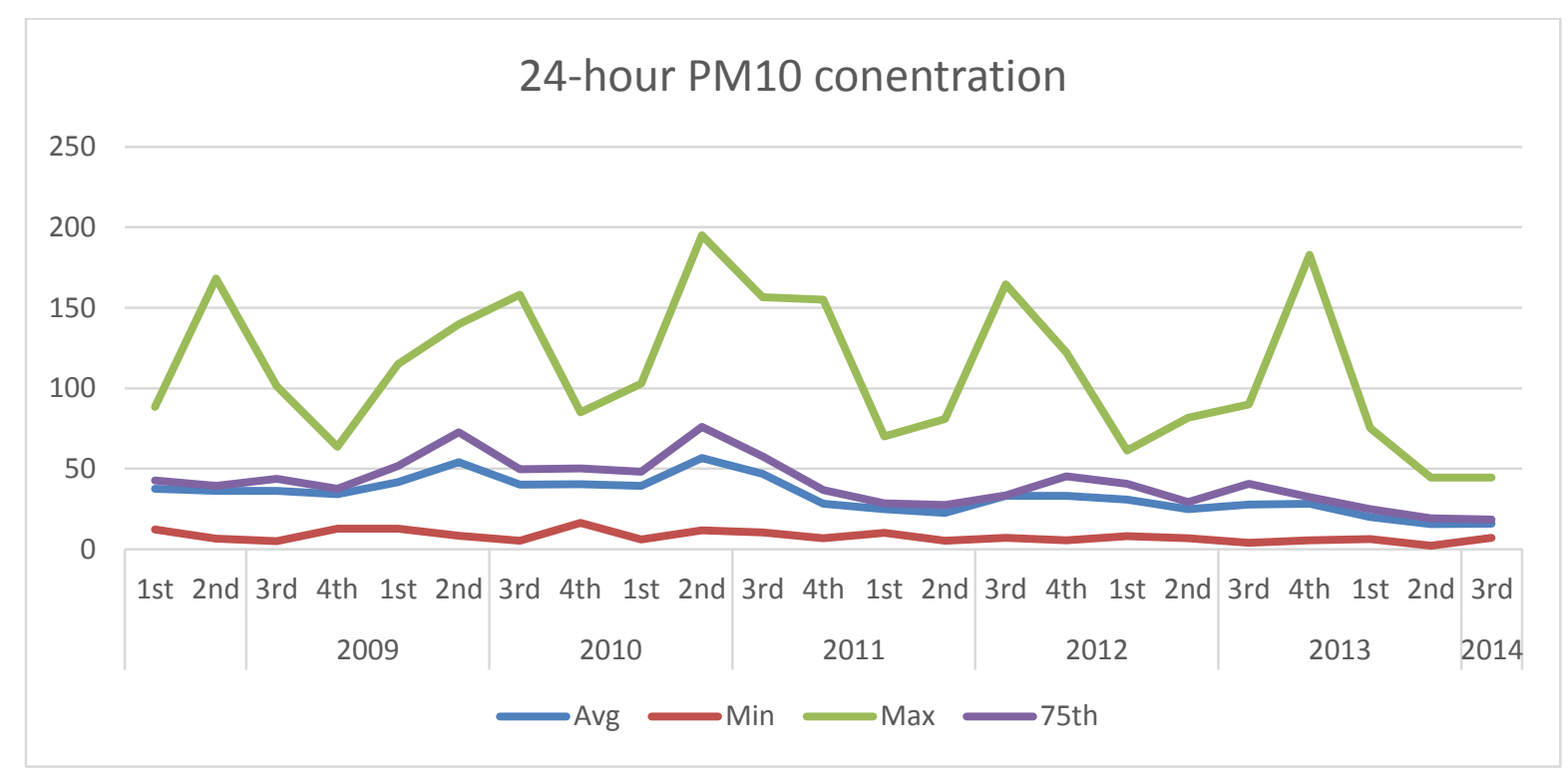

Figure 7 The 24-hour PM10 average for TEOM 4 monitors

Table 11 and figure 8 shows the PM10 concentrations as measured from 2009 through the 3rd quarter of 2014 at TEOM 5 location. This monitor is located at the Marina del sur, Berisso 
location which is about 1190 meters from the calcining facility. The maximum 24-hour average PM10 concentration was $173.8 \mu \mathrm{g} / \mathrm{m}^{3}$ in year 2011 while the average concentration for each quarter ranged from $18.9-45.3 \mu \mathrm{g} / \mathrm{m}^{3}$.

Table 11 Monthly 24-hour Average of PM10 for TEOM 5 for Time Period-1st Quarter 2009 Through 3rd Quarter 2014

\begin{tabular}{|c|c|c|c|c|c|}
\hline \multirow[b]{2}{*}{ Year } & \multirow[b]{2}{*}{ Quarter } & \multicolumn{4}{|c|}{ TEOM 5} \\
\hline & & Avg & Min & Max & $75^{\text {th }}$ \\
\hline & 1st & 26.2 & 5.8 & 81.7 & 30.5 \\
\hline & 2nd & 24.4 & 5.7 & 173.8 & 29.2 \\
\hline \multirow[t]{4}{*}{2009} & 3rd & 22 & 3.5 & 74.6 & 28.3 \\
\hline & 4th & 24.3 & 9.1 & 78.5 & 27.4 \\
\hline & 1st & 22.8 & 7.1 & 75.4 & 26.1 \\
\hline & 2nd & 19.2 & 6.7 & 53.3 & 22.8 \\
\hline \multirow[t]{4}{*}{2010} & 3rd & 20.8 & 2.2 & 60.9 & 27.8 \\
\hline & 4th & 26.6 & 8.7 & 95.7 & 31.3 \\
\hline & 1st & 21.7 & 9.1 & 83.9 & 24.4 \\
\hline & 2nd & 26.1 & 7.3 & 111.6 & 31.9 \\
\hline \multirow[t]{4}{*}{2011} & 3rd & 39.3 & 7.1 & 118.2 & 51 \\
\hline & 4th & 39.2 & 6.9 & 147.7 & 38.2 \\
\hline & 1st & 30.1 & 11 & 67.5 & 35.1 \\
\hline & 2nd & 37 & 5.9 & 107.5 & 50 \\
\hline \multirow[t]{4}{*}{2012} & 3rd & 31.2 & 6.8 & 140 & 31.8 \\
\hline & 4th & 33.3 & 5.8 & 88.3 & 40.5 \\
\hline & 1st & 36.3 & 10.7 & 131.4 & 45.6 \\
\hline & 2nd & 45.3 & 3.9 & 125.4 & 59.4 \\
\hline \multirow[t]{4}{*}{2013} & 3rd & 34.5 & 6.7 & 172 & 39.4 \\
\hline & 4th & 24.7 & 6.5 & 60.6 & 28.3 \\
\hline & 1st & 18.9 & 9.4 & 36.2 & 22.2 \\
\hline & 2nd & 21.3 & 4 & 54.6 & 25 \\
\hline 2014 & 3rd & 20.7 & 1.4 & 45.5 & 25.1 \\
\hline
\end{tabular}




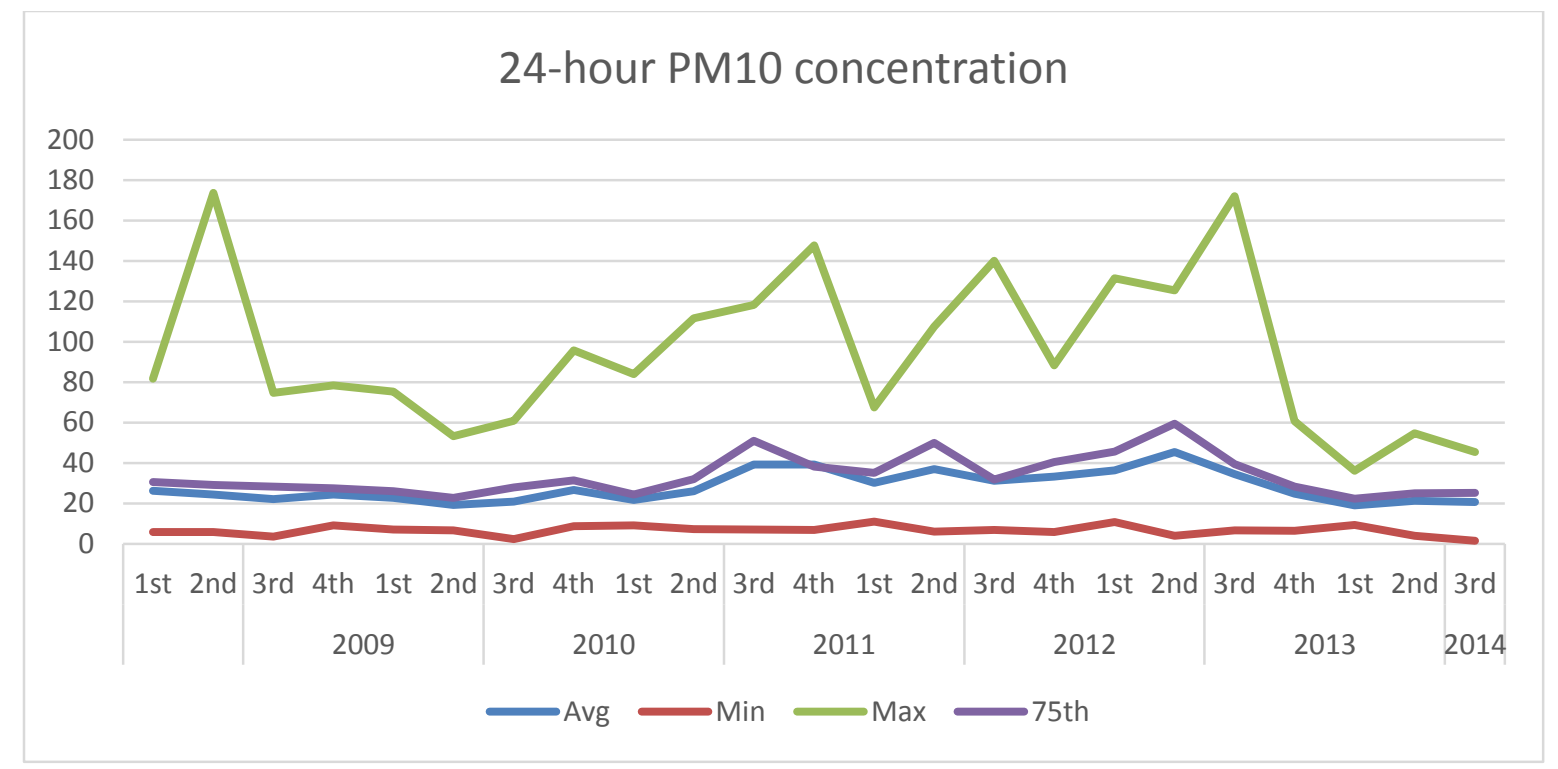

Figure 8 The figure shows the 24-hour PM10 average for TEOM 5 monitors.

Figure 9 shows the collective the quarterly average of 24-hour PM10 concentration for all three TEOM 3, 4, and 5 locations. None of the 24 -hour average concentrations was more than the standard $150 \mu \mathrm{g} / \mathrm{m}^{3}$.

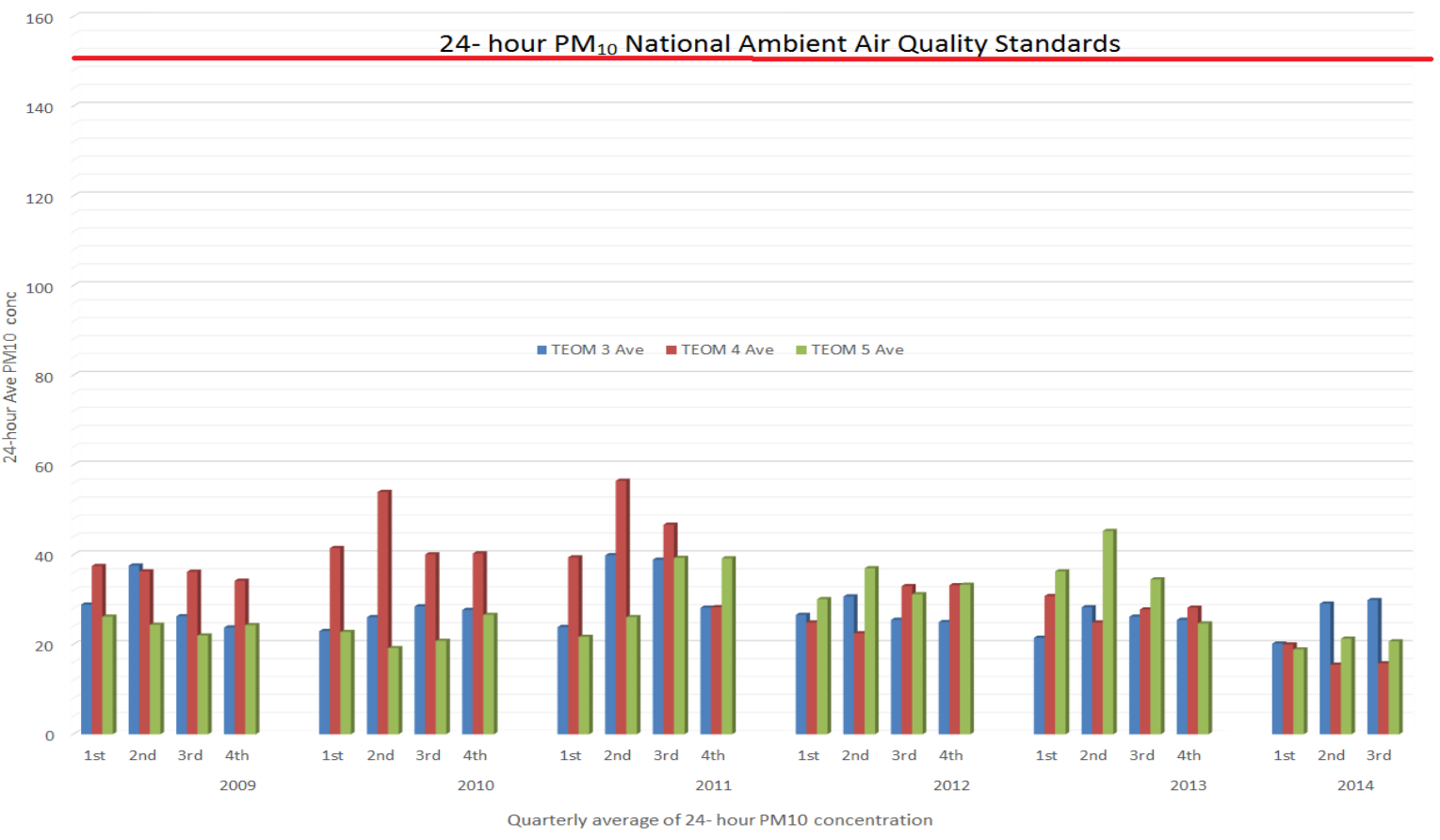

Figure 9 Quarterly Average of 24-hour PM10 Concentration for TEOM 3, 4, and 5 
Table 12 shows the number of measured PM10 values that were over the NAAQS 24hour standard of $150 \mu \mathrm{g} / \mathrm{m}^{3}$. Only three values were higher than the regulatory limit while in 2011, five values were higher than the NAAQS standard. One reading was higher than $150 \mu \mathrm{g} / \mathrm{m}^{3}$ in 2010 and 2012.

Table 12 PM10 Values Higher than the NAAQS Standard of $150 \mu \mathrm{g} / \mathrm{m}^{3}$

\begin{tabular}{|c|c|c|c|c|c|c|}
\hline TEOM & Year & Month & Day & $\begin{array}{c}\text { 24-HR } \\
\text { Ave }\left(\boldsymbol{\mu g} / \mathbf{m}^{3}\right)\end{array}$ & $\begin{array}{c}\text { Carbon } \\
\text { Fraction }\end{array}$ & $\begin{array}{c}\text { Percent of } \\
\text { Total }\end{array}$ \\
\hline 3 & 2009 & 4 & 24 & 177.24 & 3.620 & 2.04 \\
\hline 3 & 2011 & 6 & 13 & 210.33 & 3.145 & 1.50 \\
\hline 4 & 2009 & 4 & 24 & 168.20 & 3.620 & 2.15 \\
\hline 4 & 2010 & 8 & 10 & 158.15 & 9.512 & 6.01 \\
\hline 4 & 2011 & 4 & 15 & 195.05 & 3.068 & 1.57 \\
\hline 4 & 2011 & 5 & 31 & 160.94 & 2.843 & 1.77 \\
\hline 4 & 2011 & 7 & 12 & 156.53 & 3.746 & 2.39 \\
\hline 4 & 2011 & 11 & 22 & 155.07 & 2.091 & 1.35 \\
\hline 4 & 2012 & 7 & 7 & 164.47 & 5.882 & 3.58 \\
\hline 4 & 2013 & 12 & 30 & 182.90 & 3.611 & 1.97 \\
\hline 5 & 2009 & 4 & 24 & 173.80 & 3.620 & 2.08 \\
\hline 5 & 2013 & 9 & 19 & 171.95 & 3.621 & 2.11 \\
\hline
\end{tabular}

Table 13 shows the annual average PM10 concentration for year 1999-2000 and for year 2004-2006. The annual averages decreased gradually from year 2004 to 2006 with highest average concentration $\left(27.9 \mu \mathrm{g} / \mathrm{m}^{3}\right)$ was observed in year 2004 . 
Table 13 Long-Term Annual Average PM10 Concentrations for Locations near the Copetro Facility

\begin{tabular}{|c|c|}
\hline Measure/Year & PM10, $\mu \mathrm{g} / \mathrm{m}^{3}$ \\
\hline Annual Average (2004) & 27.9 \\
\hline Annual Average (2005) & 26.0 \\
\hline Annual Average (2006) & 24.4 \\
\hline Annual Average (1999-2000) (range) & $25.7(20.1-29.4)$ \\
\hline
\end{tabular}

\subsection{Black Carbon Emissions from the Calcining Facility}

Figure 10 shows the average concentrations of the ambient black carbon, which are associated with the calcining facility fugitive and stack emissions. The carbon fraction indicates the amount of emissions than can be assigned to the calcining facility since carbonaceous content is entirely from the facility and hence indicates the contribution of the calcining facility. The carbon concentrations are a small fraction of the overall concentrations seen in Table TEOM3, 4, 5 for the ambient PM10 concentrations for the same time period.

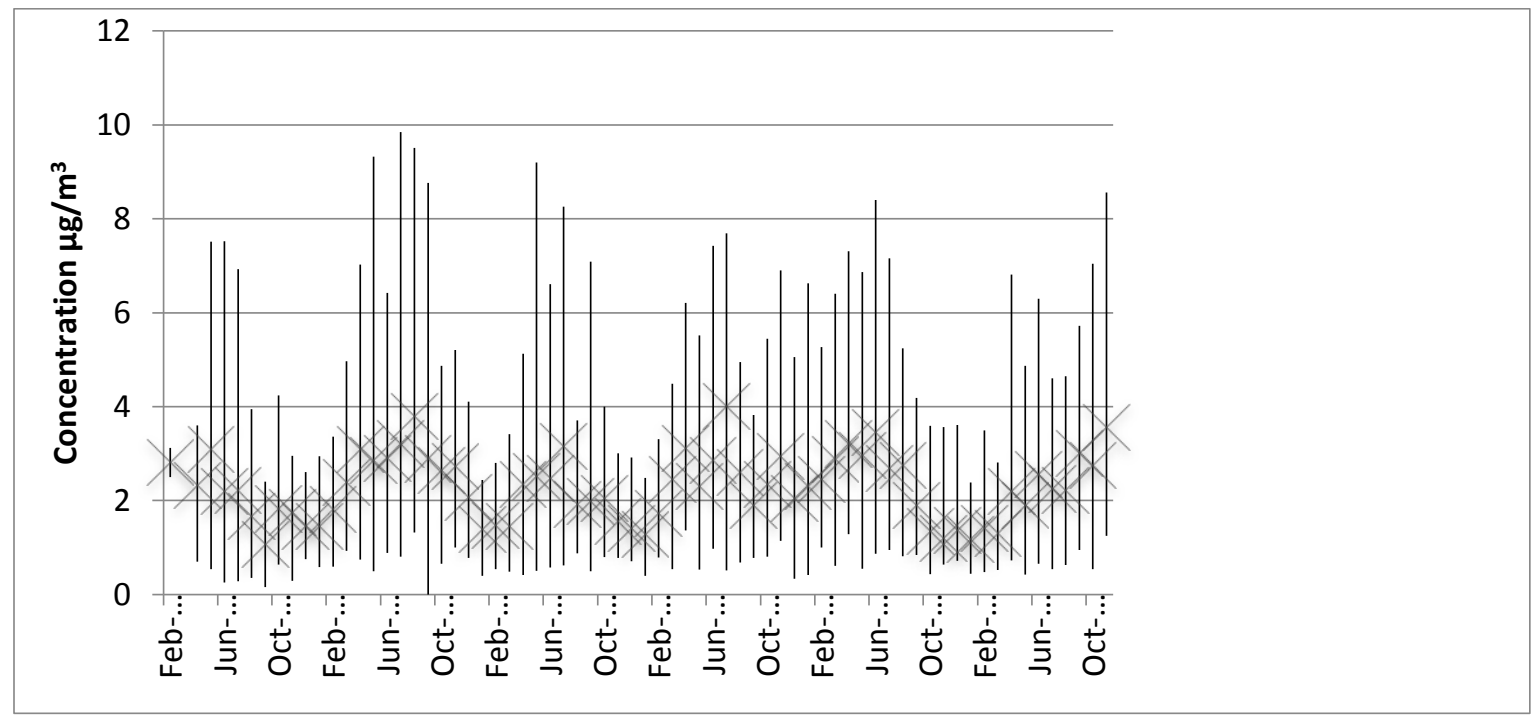

Figure 10 Black Carbon Monthly Average Concentration 


\subsection{Gaseous Emissions from the Calcining Facility}

Table 14 shows the modeled pollutant concentrations of NOx, CO, SO2 and PM10. The maximum potential emissions for all constituents from the facility were modeled using onsite meteorological data. The emission rates from stack test data for $\mathrm{CO}, \mathrm{NO}_{\mathrm{x}}, \mathrm{SO}_{2}$ and $\mathrm{PM} 10$ were scaled up to reflect the maximum production of the facility. The AERMOD dispersion model was used to determine offsite ambient concentrations. As presented in Table 14, all ambient concentrations were below local standards and EPA NAAQS levels.

Table 14 Modeled Ambient Air Concentrations

\begin{tabular}{|c|c|c|c|}
\hline \multirow{3}{*}{ Pollutant } & $\begin{array}{c}\text { Averaging } \\
\text { Period }\end{array}$ & $\begin{array}{c}\text { Modeled Concentration } \\
\left(\boldsymbol{\mu g} / \mathbf{m}^{\mathbf{3}}\right)\end{array}$ & $\begin{array}{c}\text { Standard } \\
\left(\boldsymbol{\mu g} / \mathbf{m}^{\mathbf{3}}\right)\end{array}$ \\
\hline \multirow{3}{*}{ NO $_{\mathbf{x}}$} & $1 \mathrm{hr}$ & 72.2 & 400 \\
\cline { 2 - 4 } & Annual & 2.15 & 100 \\
\hline \multirow{3}{*}{ CO } & $1 \mathrm{hr}$ & 106.1 & 40,000 \\
\cline { 2 - 4 } & $8 \mathrm{hr}$ & 79.2 & 10,000 \\
\cline { 2 - 4 } & $3 \mathrm{hr}$ & 365.4 & 365 \\
\hline \multirow{2}{*}{ SO } & $24 \mathrm{hr}$ & 215.5 & 80 \\
\cline { 2 - 4 } & Annual & 11.8 & 150 \\
\hline \multirow{2}{*}{ PM10 } & $24 \mathrm{hr}$ & 2.8 & 50 \\
\cline { 2 - 4 } & Annual & 0.04 & 1300 \\
\hline
\end{tabular}




\section{CHAPTER FIVE: DISCUSSION}

The primary purpose of the current study was to evaluate the emission risks from the calcining facility. Our results showed that both the normal and the maximum calcining facility operations, produced air emissions that were lower than the USEPA standards promulgated to

protect the public health. The emissions included the actual facility emissions from the processing of green coke as well as the emissions from the handling and storage of raw materials at the facility.

\subsection{Particulate Matter from Calcining Process and Public Health Risks}

Based on the results from figure 9, the emissions from the coke calcining facility under the normal conditions were below the public health standards set up by the regulatory agencies. These emissions were from the handling and the storage of raw material, green coke, as well as from the green coke processing to produce the final product, calcined coke. There was negligent amount of volatile organic compounds collected during the emissions sampling, as high temperatures of the calcining process destroyed about $99 \%$ of the volatile compounds. The trend for the $\mathrm{Hi}$ Vol/TEOM measurements at site $\mathrm{A}$ and $\mathrm{B}$ in Table 8 suggested that the difference in the measurements from Hi-Vol and TEOM monitors could be assigned to the prevailing pollution conditions in the petrochemical complex. The Hi-Vol monitors usually record higher concentrations of PM10 compared to the TEOM monitors. It is due to the fact that the TEOM monitors heat up the filter destroying or repelling the semi-volatile organic mass. In contrast, the 
Hi-Vol monitors record both the semi-volatile materials as well as PM leading to higher concentrations recorded by the Hi-Vol compared to the TEOM monitors. Additionally, ammonia nitrates are among the most common volatiles removed by the TEOM monitors (Charron et al., 2004). Ammonia nitrates are not processed/ produced in any calcining process indicating that the nitrates expelled by the monitors are mostly from external sources such as traffic emissions and other industrial activities.

In the current study, the very low reading of the TEOM monitor for PM10 concentrations indicated that the calcining facility produced emissions at much lower concentrations than the regulatory levels $\left(150 \mu \mathrm{g} / \mathrm{m}^{3}\right)$ established by USEPA to protect the public health. The 24-hour annual averages for the TEOMs 3, 4, and 5, were $34.61 \mu \mathrm{g} / \mathrm{m}^{3}, 41.66 \mu \mathrm{g} / \mathrm{m}^{3}$, and $38.02 \mu \mathrm{g} / \mathrm{m}^{3}$, respectively, all below the average of $50 \mu \mathrm{g} / \mathrm{m}^{3}$ set up by the Argentinian regulatory agencies. The readings that exceeded the regulatory standards are from the TEOM monitors located 850 meters from the source calcining facility, Copetro. These 'higher' concentrations could have resulted from other sources of pollution such as garbage burning, traffic, or other industrial activity in the petroleum complex. Given the low measurements from the monitors at the calcining facility, we concluded that the contributions of the petroleum coke calcining facility, Copetro to the total emissions in the complex is de minimis.

Further, the calcining facility's contribution to the total emissions in the area could also be estimated from the black carbon concentration in the measured PM10 levels. A shown in figure 10, the carbon black concentration formed a miniscule fraction of the total overall PM10 concentration. Additionally, it is important to mention that the black carbon concentration recorded by the monitors could not be solely attributed to the calcining facility as there are other sources of black carbon such as the diesel vehicular traffic. Given the low black carbon 
concentration, it could be concluded that the calcining facility represented as a small contributor to the overall PM10 emissions. Table 11 indicated the PM10 measurements exceeding the regulatory standard of $150 \mu \mathrm{g} / \mathrm{m}^{3}$. For years $2008-2010$ and years $2012-2014$, TEOMs 3, 4, and 5 readings did not exceed $150 \mu \mathrm{g} / \mathrm{m}^{3}$, thus satisfying the set standard of one measure allowed over the limit of $150 \mu \mathrm{g} / \mathrm{m}^{3}$ PM10 per year averaged over 3 years. For years $2009-2011,2010-2012$, and 2011 - 2013, only one monitor (TEOM 4) had six readings that were over the limit of 150 $\mu \mathrm{g} / \mathrm{m}^{3}$ PM10 per year averaged over 3 years. Though the values from the TEOM 4 exceeded the set standards, the black carbon concentration representing the calcining facility contribution was less than $7 \%$ of the total PM10 concentration. Thus, it could be concluded that the other sources of pollution in the industrial area contributed to the total PM10 concentrations.

\subsection{Gaseous Emissions from Calcination Process and Public Health Risks}

The modeled concentrations as shown in Table 13 were well below the standards set up by USEPA NAAQS. These emissions were measured from two kiln ovens on a monthly basis. The emissions from the calcining facility were scaled up to reflect maximum emissions from the facility. The AERMOD modeling suggested that any potential emissions from the calcining facility would be minimal and would represent only about $20 \%$ of the standards.

\subsection{Epidemiological Review: Health risks from Petrochemical Emissions}

By the year 2000, around 730 refineries worldwide were producing about 4 billion tons of crude oil each year (Mudu et al., 2014). Multiple steps involved in the processing of crude oil including the handling and the storing of raw materials and processed products, have the tendency to produce chemical hazards and emit toxic pollutants in the surroundings. According to WHO, about 4.9 million deaths around the world have been attributed to exposure to chemical hazards from 
industrial activities. Hence, there is an urgent need to accurately identify and characterize the risk and adverse health effects associated with the petrochemical emissions.

The characterization of exposure from the industries requires comprehensive data on the trends (spatial and temporal) of the chemical and pollutants emitted from the industry. In addition, the assessment requires considering changing patterns such as climate variability and population mobility from one industrial setting to other diverse settings. Since two similar industries in two different settings could lead to varied emissions, the epidemiological studies must consider the confounding factors while determining the health risks from such industries. Additionally, a thorough and exhaustive assessment of the pollutant risk is essential as an expensive industrial cleanup not only pushes the budgetary constrains but it also impacts the perception in the residents living in the vicinity of the facilities. Studies have shown that even the odor of the emissions from the industries influence the residents' perceptions of health risk from the industries (Luginaah et al., 2000). Petrochemical industries located near the residential areas pose a health hazard to the population residing in and around those areas, specially the susceptible populations including the children and the elderly. Studies have shown that the perceived health risk by the exposed population may impact their health, such as negative thoughts and stress about the industries' emissions could lead to poor mental and physical health (Keller et al., 2012).

Various studies have evaluated the effect of petrochemical pollutants including the Particulate Matter on the human health. These studies have included both the acute as well as the chronic effects on respiratory and cardiovascular health of the exposed populations and have assessed the role of PM and gaseous pollutants from the petrochemical industries, and combustion and mobile sources in producing the adverse health effects. Mortality studies have assessed the number of deaths occurring during a specific time period and the exposure levels during 
the time periods. Morbidity studies have involved the study of hospital admission rates, symptoms, disease, levels of lung functions, or restricted activity.

These studies have involved the subjects from all age groups including the susceptible populations such as children and older people. It is hard to separate and individualize various processes involved in the petroleum complex. There is a need to find a distinction between the petrochemical industries, oil refineries, and calcining industries. Petrochemical industries deal with various processes and include multitude of chemicals (benzene, ammonia etc.) while producing products such as solvents, fertilizers, plastics, and explosives. For example, oil refinery is the industrial complex where the crude oil is refined to produce gasoline or diesel, kerosene oil, lubricating oils, and petroleum coke. Calcining facility is an industry that converts the petroleum coke to calcined coke, which can be used in the aluminum and anode production.

\subsection{Review of Epidemiological Studies on Petrochemical Emissions}

Various epidemiological studies have attempted to identify the adverse health risks associated with the petrochemical emissions (Ware et al.,1993; White et al., 2009; Wichmann et al., 2009; Nilsa I Loyo-Berrios et al., 2007; Yang et al., 1998; Smargiassi et al., 2009; Rovira et al., 2014; de Moraes et al., 2010; Chen et al., 1998; Liao et al., 2009; Meo et al., 2015; Wichmann et al., 2009; Kaldor et al., 1984; Sans et al., 1995; Belli et al., 2004; Simonsen et al., 2010; Yang et al., 1999; Passetto et al., 2008). However, there are contrasting results among the studies in terms of the health risks associated with various pollutants. The uncertainty from the epidemiological studies may be due to the inadequate exposure assessment, ubiquitous nature of pollutants, poor and limited emission data, single pollutant and co-pollutant variability, and varied adverse health response in diverse populations. Some epidemiological studies also undermined the additional health risks 
already prevalent in the society (e.g. living close to highways or highly congested areas) or the health risks associated with a sub-population (children vs adults).

The complexity in determining the specific source(s) of air pollutants from one or multiple sources in the diverse environmental surroundings, and its varied degree of effect on the human health such as higher impact on susceptible populations, may lead to the mismatch between the risk from a specific source and the policy regulations imposed to amend the risk. Therefore, the last aim of the study was to compare the epidemiological studies conducted on the emissions from the petroleum complex in order to better understand the health risks associated with the pollutants. The epidemiology review will help adopt a more persistent approach to undertake more consistent policy responses and pollutant regulations.

The epidemiological studies assessing the respiratory risk from the petrochemical industries are summarized in Table 14. The specific respiratory conditions examined in the studies were asthma (Ware et al.,1993; White et al., 2009; Wichmann et al., 2009; Nilsa I Loyo-Berrios et al., 2007; Yang et al., 1998; Smargiassi et al., 2009), hospitalization rates from respiratory signs and symptoms (Rovira et al., 2014), other respiratory symptoms such as wheezing, shortness of breath (de Moraes et al., 2010; Chen et al., 1998; Liao et al., 2009), lung functions (Meo et al., 2015; Wichmann et al., 2009), and incidence/ mortality of lung cancer (Kaldor et al., 1984; Sans et al., 1995; Belli et al., 2004; Simonsen et al., 2010; Yang et al., 1999; Passetto et al., 2008).

Majority of the studies calculated the odds ratio to determine the association between the respiratory risk and the petrochemical emissions. Specifically, the odds ratio (OR) of asthma or asthma exacerbation from the petrochemical emissions varied from as low as 0.08 to 1.01 (Chen et al. 1998), 1.06 (White et al., 2009), 1.27 (Ware et al. 1993), 1.44 (Loyo-Berrios et al., 2007), and finally as high as 2.01 (de Moraes et al., 2010) and 2.76 (Yang et al., 1998). All these studies were 
conducted in children below 17 years of age and had utilized parent questionnaires, and hospital and emergency visits to measure the exposed populations. Further, in terms of studies on adult population, Meo et al. (2015) and Maestrelli et al. (2001) observed lower lung functions in the industry workers at Saudi Arabia and Italy petrochemical industry. Simonsen et al. (2010) and Belli et al. (2004) examined an odds ratio of lung cancer in residents exposed to the petrochemical industries, with 1.45 odds ratio for residents living within $0.8 \mathrm{~km}$ (Simonsen et al., 2010) to 3.1 for residents living within $3 \mathrm{~km}$ of the petrochemical industry (Belli et al., 2004). Majority of the studies mentioned had an adequate study design (ecological, cross sectional or cohort studies) and disease measures (respiratory symptoms, lung function volumes lung cancer), but the studies did not report the length of time the petrochemical industry was operational and the subsequent duration of exposure from the specific industrial source. This may confound one of the most important factor in risk characterization, namely the exposure assessment. All of the studies mentioned in Table 14 have little information of the specific exposure from the source(s) and no description of the exposure patterns or changes over time. These studies have thus undertaken a pre-conceived notion of higher risk with proximity to the location of the source i.e. the petrochemical industry. 
Table 15: Review of Epidemiological Studies on Petrochemical Emissions

\begin{tabular}{|c|c|c|c|c|}
\hline Study & $\begin{array}{l}\text { Study } \\
\text { population }\end{array}$ & Type of study & Study methods/Emissions analyzed & Results \\
\hline $\begin{array}{l}\text { Ware et al. (1993), } \\
\text { USA }\end{array}$ & Children & $\begin{array}{l}\text { Cross- } \\
\text { sectional study }\end{array}$ & $\begin{array}{l}\text { Children studying in schools within the vicinity of } \\
\text { petroleum complex (in valley) compared to students } \\
\text { outside the valley. Pollutants analyzed were: } 5 \text { petroleum- } \\
\text { related compounds, and combination of } 10 \text { compounds } \\
\text { specific to industrial processes. }\end{array}$ & $\begin{array}{l}\text { School children in the valley had higher rates of asthma } \\
(\mathrm{OR}=1.27) \text { and a higher rate of chronic lower } \\
\text { respiratory symptoms }(\mathrm{OR}=1.13) \text {, than school children } \\
\text { outside valley. }\end{array}$ \\
\hline $\begin{array}{l}\text { Rovira et al. (2014), } \\
\text { Spain }\end{array}$ & Children & $\begin{array}{l}\text { Cross- } \\
\text { sectional study }\end{array}$ & $\begin{array}{l}\text { Respiratory health of children residing in petrochemical } \\
\text { complex areas compared with children residing in low } \\
\text { pollution level areas. }\end{array}$ & $\begin{array}{l}\text { Children residing near petrochemical areas had higher } \\
\text { prevalence of hospitalization rate (prevalence rate } \\
=1.49) \text { and cough }(\mathrm{PR}=1.29) \text { than children living in low } \\
\text { pollution areas }\end{array}$ \\
\hline $\begin{array}{l}\text { White et al. (2009), } \\
\text { South Africa }\end{array}$ & Children & $\begin{array}{l}\text { Cross- } \\
\text { sectional study }\end{array}$ & $\begin{array}{l}\text { Occurrence of respiratory symptoms were compared with } \\
\text { meteorologically estimated exposure (MEE), and with } \\
\text { simple distance from the refinery }\end{array}$ & $\begin{array}{l}\text { Asthma incidence was associated with simple distance } \\
\text { from the refinery, } \mathrm{OR}=1.06 \text { while higher asthma } \\
\text { association was observed with meteorologically } \\
\text { associated exposure, } \mathrm{OR}=1.81\end{array}$ \\
\hline $\begin{array}{l}\text { Wichmann et al. } \\
\text { (2009), Argentina }\end{array}$ & Children & $\begin{array}{l}\text { Cross- } \\
\text { sectional study }\end{array}$ & $\begin{array}{l}\text { Occurrences of asthma rates, asthma exacerbations, } \\
\text { respiratory disease symptoms compared in children } \\
\text { residing near a petrochemical complex, near traffic areas } \\
\text { and two unpolluted regions }\end{array}$ & $\begin{array}{l}\text { Children living near the petrochemical plant had higher } \\
\text { asthma rates }(\mathrm{OR}=2.76) \text {, higher asthma exacerbations } \\
(\mathrm{OR}=1.88) \text { and higher wheezing incidence }(\mathrm{OR}=1.93) \text {, } \\
\text { and lower lung function ( }>13 \% \text { decrease in FEV1 } \\
\text { percent predicted) than those living in other regions }\end{array}$ \\
\hline $\begin{array}{l}\text { Loyo-Berrios et al. } \\
\text { (2007), Puerto Rico }\end{array}$ & $\begin{array}{l}\text { Children } \\
\text { under } 17 \\
\text { years }\end{array}$ & $\begin{array}{l}\text { Nested case } \\
\text { control study }\end{array}$ & $\begin{array}{l}\text { Risk of asthma compared in children residing in air } \\
\text { pollution areas with control }\end{array}$ & $\begin{array}{l}\text { The study noted higher asthma attacks in children living } \\
\text { near a grain mill (odds ratio }(\mathrm{OR})=1.35) \text {, petroleum } \\
\text { refinery }(\mathrm{OR}=1.44)\end{array}$ \\
\hline
\end{tabular}


Table 15 (Continued)

\begin{tabular}{|c|c|c|c|c|}
\hline Study & $\begin{array}{l}\text { Study } \\
\text { population }\end{array}$ & Type of study & Study methods/Emissions analyzed & Results \\
\hline $\begin{array}{l}\text { Yang et al. (1998), } \\
\text { Taiwan }\end{array}$ & Children & $\begin{array}{l}\text { Cross- } \\
\text { sectional study }\end{array}$ & $\begin{array}{l}\text { Children residing in petrochemical areas compared to } \\
\text { children in non-petrochemical areas }\end{array}$ & $\begin{array}{l}\text { The children residing in the petrochemical complex had } \\
\text { rate of asthma }(\mathrm{OR}=2.76) \text { and higher rate of upper } \\
\text { respiratory symptoms }(\mathrm{OR}=1.51)\end{array}$ \\
\hline $\begin{array}{l}\text { de Moraes et al. } \\
\text { 2010, Brazil }\end{array}$ & $\begin{array}{l}\text { Children }(0- \\
14 \text { years })\end{array}$ & Cross sectional & $\begin{array}{l}\text { Children living within } 5 \mathrm{~km} \text { of petrochemical complex } \\
\text { compared with non-exposed reference communities }\end{array}$ & $\begin{array}{l}\text { Statistically significant associations was observed for } \\
\text { wheezing and living in exposed communities }(\mathrm{OR}=2.01)\end{array}$ \\
\hline $\begin{array}{l}\text { Smargiassi et al., } \\
2009 \text {, Canada }\end{array}$ & $\begin{array}{l}\text { Children }(2-4 \\
\text { years })\end{array}$ & $\begin{array}{l}\text { Case cross- } \\
\text { over study }\end{array}$ & $\begin{array}{l}\text { Children residing within } 7.5 \mathrm{~km} \text { of the petroleum } \\
\text { complex/ Risk of asthma compared with the short term } \\
\text { changes in SO2 levels }\end{array}$ & $\begin{array}{l}\text { Days with higher } \mathrm{SO} 2 \text { peaks were associated with } \\
\text { asthma related visits }(\mathrm{OR}=1.10) \text { and hospital } \\
\text { admissions }(\mathrm{OR}=1.42)\end{array}$ \\
\hline $\begin{array}{l}\text { Meo et al., 2015, } \\
\text { Saudi Arabia }\end{array}$ & $\begin{array}{l}\text { Workers in } \\
\text { petroleum } \\
\text { industry }\end{array}$ & Cross sectional & $\begin{array}{l}\text { Lung function values were measured in exposed workers } \\
\text { and compared to control population }\end{array}$ & $\begin{array}{l}\text { Lowered lung function volumes including lower FEV1, } \\
\text { FEV1/FVC Ratio, PEF, FEF } 25 \% \text {, FEF-50 \% among oil } \\
\text { refinery workers compared to their controls. }\end{array}$ \\
\hline $\begin{array}{l}\text { Chen et al., 1998, } \\
\text { China }\end{array}$ & Children & $\begin{array}{l}\text { Cross- } \\
\text { sectional study }\end{array}$ & $\begin{array}{l}\text { Children residing in petrochemical areas and urban } \\
\text { locations compared to children in rural areas/ } \\
\text { Questionnaire were filled by parents to assess children } \\
\text { respiratory symptoms }\end{array}$ & $\begin{array}{l}\text { OR for occurrence of shortness of breadth in three } \\
\text { Petrochemical locations were } 1.01,1.05 \text {, and } 0.08 \text { and } \\
\text { OR for chronic cough was } 1.26, .0 .88 \text {, and } 1.08 \text {. OR for } \\
\text { bronchitis for } 3 \text { locations were } 1.23,1.01 \text {, and } 1.17 \text {. }\end{array}$ \\
\hline $\begin{array}{l}\text { Liao et al., 2009, } \\
\text { China }\end{array}$ & Children & $\begin{array}{l}\text { Cross- } \\
\text { sectional study }\end{array}$ & $\begin{array}{l}\text { Respiratory symptoms compared in children residing in } 4 \\
\text { locations: petrochemical complex, close to wasteland, } \\
\text { coastal area, other parts of the country }\end{array}$ & $\begin{array}{l}\text { Children residing in petrochemical complex had higher } \\
\text { rates of dry cough }(3.6 \%) \text { and prevalence of wheezing } \\
(3.7 \%)\end{array}$ \\
\hline
\end{tabular}


Table 15 (Continued)

\begin{tabular}{|c|c|c|c|c|}
\hline Study & $\begin{array}{l}\text { Study } \\
\text { population }\end{array}$ & Type of study & Study methods/Emissions analyzed & Results \\
\hline $\begin{array}{l}\text { Maestrelli et al. } \\
\text { (2001), Italy }\end{array}$ & Adults & Cohort study & $\begin{array}{l}\text { Association of changes in asthma and lung function with } \\
\text { changes to PM10, PM2.5 exposure over } 2 \text {-year period }\end{array}$ & $\begin{array}{l}\text { An increase in SGRQ scores and lowered ACT scores } \\
\text { were associated with } 10 \mu \mathrm{g} / \mathrm{m} 3 \text { increase in PM10 } \\
\text { personal exposure. No association with changes in } \\
\text { FEV1 with PM10 }\end{array}$ \\
\hline $\begin{array}{l}\text { Kaldor et al. (1984), } \\
\text { USA }\end{array}$ & Adults & $\begin{array}{l}\text { Ecological } \\
\text { study }\end{array}$ & $\begin{array}{l}\text { Rates of lung cancer in populations residing at four } \\
\text { locations: Without industrial exposure, } 2 \text { locations with } \\
\text { industrial exposure without petrochemical exposure, } 4 \text { th } \\
\text { location with petrochemical exposure }\end{array}$ & $\begin{array}{l}\text { Males exposed to petrochemical emissions exposure had } \\
\text { higher prevalence of lung cancer than non exposed. No } \\
\text { association in females }\end{array}$ \\
\hline $\begin{array}{l}\text { Sans et al. (1995), } \\
\text { United Kingdom }\end{array}$ & Adults & $\begin{array}{l}\text { Mortality } \\
\text { study }\end{array}$ & $\begin{array}{l}\text { Mortality rates observed in residents within } 7.5 \mathrm{~km} \text { of } \\
\text { petrochemical complex }\end{array}$ & $\begin{array}{l}\text { Standardized Mortality Ratio (SMR=1.07) was } \\
\text { observed in adults residing within } 3 \mathrm{~km} \text { of the } \\
\text { petrochemical complex }\end{array}$ \\
\hline $\begin{array}{l}\text { Belli S., et al. } \\
\text { (2004), Italy }\end{array}$ & Mortality & $\begin{array}{l}\text { Case control } \\
\text { study }\end{array}$ & $\begin{array}{l}\text { Cancer mortality was observed with increasing distance } \\
\text { from the petrochemical plant }\end{array}$ & $\begin{array}{l}\text { Lung cancer in residents living within } 3 \mathrm{~km} \text { of } \\
\text { petrochemical plant, } \mathrm{OR}=3.1\end{array}$ \\
\hline $\begin{array}{l}\text { Simonsen et al. } \\
\text { (2010), USA }\end{array}$ & Adults & $\begin{array}{l}\text { Population- } \\
\text { based case- } \\
\text { control study }\end{array}$ & $\begin{array}{l}\text { Lung cancer incidence was observed in residents living in } \\
\text { vicinity of petrochemical plant }\end{array}$ & $\begin{array}{l}\text { Residents living within } 0.8 \mathrm{~km} \text { had higher incidence of } \\
\text { lung cancer }(\mathrm{OR}=1.45)\end{array}$ \\
\hline $\begin{array}{l}\text { Yang et al. (1999), } \\
\text { China }\end{array}$ & Adults & $\begin{array}{l}\text { Population- } \\
\text { based case- } \\
\text { control study }\end{array}$ & $\begin{array}{l}\text { Lung cancer incidence was observed in residents living in } \\
\text { vicinity of oil refinery }\end{array}$ & $\begin{array}{l}\text { Standardized Mortality ratio (SMR=144.5) in residents } \\
\text { after living for } 37 \text { years in the vicinity of the } \\
\text { petrochemical complex }\end{array}$ \\
\hline $\begin{array}{l}\text { Passetto R et al. } \\
\text { (2008), Italy }\end{array}$ & $\begin{array}{l}\text { Workers form } \\
\text { petroleum } \\
\text { industry }\end{array}$ & Cohort study & $\begin{array}{l}\text { Mortality rates from lung cancer observed in workers in } \\
\text { petrochemical complex }\end{array}$ & $\begin{array}{l}\text { The rate ratio of lung cancer in workers was observed to } \\
\text { be } 1.66 \text { ( } 90 \% \text { CI- } 1.07-2.58)\end{array}$ \\
\hline
\end{tabular}




\subsection{Critique on Ambient Air Pollution Epidemiological Studies}

The association between the emissions from pollutant sources (e.g. petrochemical industries) and their adverse health effects (e.g. asthma, lung cancer) are dependent upon multiple factors including the individual properties of the pollutants, interactions of the pollutant with other co-existing pollutants in the air, varied exposure patterns and pathways, and lastly the diverse social and economic factors of the population at risk for exposure. Few selected studies have examined the effect of air pollutants in the residential areas, i.e. the effects on the health of the residents, mainly the children. (Rusconi et al., 2011; White et al., 2009; Smargiassi et al., 2009; Wichmann et al., 2009). Though these authors drew conclusions regarding the potential association of the particulates and their respiratory health outcomes, none of these studies were able to demonstrate specific diagnostic criteria in subjects to provide an objective diagnosis of the disease. Additionally, none of these studies were able to determine that the petrochemical industries were the sole source of exposures measured in the studies. Smargiassi et al. (2009) studied the effect of $\mathrm{SO}_{2}$ from point sources on asthma hospitalizations of children near petroleum refineries in Montreal, Canada. Though the study pointed out that short term exposure to $\mathrm{SO}_{2}$ led to the higher rates of asthma hospitalization, the exposure group (i.e. children between 2 and 4 years) was an inadequate representation of the exposed population. The study assumed that the children were 'exposed' to the ambient air pollution. However, the observation that the exposed group spent the majority of their time inside their houses, emphasis that children were not a true exposure group and hence, it undermines the associations derived in the study. Additionally, the authors were unable to locate the specific sources of emissions and failed to ascertain the exposure levels of the subjects. This further questions the association drawn in the study regarding the actual 
potential risk from the suspected exposures. Below, we have provided a brief review of the epidemiological studies.

The use of qualitative assessment techniques such as questionnaires to determine the illeffects of air pollutants, especially in high pollution areas, is inadequate and generally obscures the outcomes or results of the study. Most of the studies utilize the questionnaires to report changes in health symptoms/ signs experienced by the exposed population. In such scenarios, the exposed group might overestimate the health effects and report a mere discomfort as 'increase in symptoms', indicating that the air pollutant has a negative effect on the exposed group compared to the unexposed group. However, these self-reports of 'increased symptoms' are unreliable as they are not equivalent to medically monitored/ examined symptoms. White et al. (2009) studied the effect of vicinity to a petrochemical complex on the respiratory health of children including their asthma exacerbations. The study indicated a higher prevalence of asthma symptoms in children residing in the vicinity of the petroleum industry. Moreover, the study grouped the children as 'diseased' and 'non diseased' based on the responses of the study questionnaire. Similar procedures of measuring or surveying disease is not representative of actual exposure and outcome, as there is a huge risk of under-estimation or over-estimation by the study participants. Another study examined the effect of oil refinery pollution on the asthma symptoms and lung function in children and adults residing near petrochemical industries (Rusconi et al., 2011). The study showed that lowering of the lung functions along with bronchial inflammation in the exposed population was associated with residing near the petrochemical areas as compared to the non exposed population. However, it is interesting to note that the selection of 'exposure and non exposure population' was determined by the responses on a questionnaire regarding the respiratory symptoms and associated risk factors. Overall, we can say that the studies employing 
questionnaires as the singular means of obtaining information about an exposure group, may fail to adequately ascertain the reports for 'increased symptoms' to the nearby pollution sources (i.e. petrochemical complex).

The presence of an industrial complex (petrochemical, calcining facility) does not automatically indicate increased emission risk to the residents of the area. The ill-effects from the emissions of an industrial complex (such as Particulate matter, VOC's or gaseous content) is not solely guided by the presence or absence of the facility but by various other contributing factors such as the anthropogenic sources, as well as the control measures employed by the facility. Wichmann et al. (2009) studied the role of petrochemical industry as a contributing factor in the exacerbations of asthma and other respiratory symptoms in children residing in the area. The study reported that the presence of the main petrochemical complex in the residential area indicates a 'higher risk' of respiratory symptoms and asthma exacerbations. However, we would like to rebut that the mere presence of the facility is an indicator of ill-effects, instead the level of air pollutants in the area are equally important. More importantly, it is essential to recognize the sources of these pollutants as it would help the regulatory agencies to localize the source and control the emissions.

There are various other sources of Particulate Matter and gaseous pollutants in the air including the motor vehicles, unpaved roads, and fuel combustion at homes especially during winters as the combustion rates are higher in winters. The amount of pollutants emitted from these additional sources may differ in amount (though not in quality) and thus may contribute to the health effects.

Majority of the epidemiological studies examine the effects of a mixture of pollutants by determining the individual pollutant concentration. Both co-pollutant and multi-pollutant methods have been utilized in the past to derive the exposure concentrations of the pollutants. The studies 
examining the effects of multiple pollutants at a single period of time are generally plagued by various factors which may effect the strength of associations measured in the study. These include but are not limited to the inter and intra variations of the pollutant, unknown pollutant acting as a confounder, interactions among the pollutants while producing the health effects, and the exposure uncertainty. Loyo-Berrios et al. (2006) noted that the asthmatics living near the sources of air pollution have higher risk of asthma attacks, the odds ratio were found to be between 1.28 and 1.44 for the asthmatics as compared to the non-asthmatics. However, in this study, the asthma exacerbations were attributed to the air pollution sources without providing any information on the specific sources of pollutants.

Ambient air pollution is a result of conglomerate of multiple sources and pollutants. In the studies including single pollutant models, the association may be significant if the pollutant does not interact with other pollutants in the air and instead, acts as an independent risk factor. However, majority of the pollutants do not act independently and usually correlate (positively or negatively) with other pollutants. For example, the gaseous pollutants such as $\mathrm{NO}_{\mathrm{x}}, \mathrm{SO}_{2}, \mathrm{CO}$ are known to cause adverse health effects similar to those caused by the Particulate Matter. Hence, it would be difficult to ascertain the effects of these gaseous pollutants on human health as they have a high degree of correlation with the Particulate Matter in the ambient environment. It is even more relevant when the PM, VOC's or gaseous pollutants have common sources of emission. Additionally, $\mathrm{PM}, \mathrm{SO}_{2}$ and $\mathrm{CO}$ are produced from both, motor vehicles combustion as well as from petro chemical industries. Assigning the pollutant to a particular source is difficult in the actual environmental conditions and hence, it would be difficult to determine the actual risks of a petrochemical industry. 
On the other hand, the epidemiological studies analyzing the effects of multiple pollutants along with their correlations, fail to consider the power of association of individual pollutants. Some studies have attempted to measure the individual effects of the air pollutants and their association with health effects. Atkinson et al. (1999) noted that in one-pollutant models PM10, $\mathrm{NO}_{2}$, and $\mathrm{SO}_{2}$ were significantly associated with the increase in asthma cases but when the pollutants were studied in a multi pollutant model i.e., when the pollutants were added to another pollutant, the statistical significance decreased thereby suggesting that these pollutants can not act independently in the ambient atmosphere. Usually, it is difficult to separate the health effects of the air pollutant individually because of the existing correlations. This was observed by Ilabaca et al. (1999) while observing the effects of the particulate fine particles on the respiratory health of children in Santiago.

The impact of the pollutants cannot be observed in seclusion but the admission that the multiple pollutants may act as confounders, is required while deriving the outcomes on human health. Wichmann et al. (2009) derived an association between the multiple pollutants and the respiratory health effects by monitoring the daily ambient air pollutants for four weeks. This association needs to be understood by acknowledging the possible interactions among various pollutants. The results thus obtained from similar studies would be unable to assign a specific role of each pollutant, as well as unable to identify the source of the pollutant. This highlights the fact that there is no one correct approach to assess the exposure levels of the individual pollutants that can appropriately assess the exposure-outcome association.

Majority of the epidemiological studies have examined the association of ambient Particulate Matter with acute respiratory effects including the exacerbation of asthmatic attacks/ symptoms, increase or decrease in medication use, and hospital or emergency ward 
admissions. Although most of the studies obtained an association between PM and respiratory symptoms including chest tightness, cough, difficulty breathing and rhinitis, majority of these associations were not statistically significant.

According to American Thoracic Society, FEV1 and FVC values are considered 'normal' if the values are above $80 \%$. The pulmonary defects due to lowered lung function is a useful tool if the spirometry values of FVC, FEV1, FEV1/FVC, and TLC are below the $5^{\text {th }}$ percentile of the normative data. However, if the values are close to the upper or the lower limits of the normal values, then the literal interpretation of the results is difficult along with accurate estimation of the lung functions. In these situations, further assessment is required to label a lung function as 'abnormal'. Commonly FEV1 values less than $80 \%$ and FEV1/FVC values lower than 0.7 are used as standards while assessing the lung functions, and values below these are considered 'below normal'. Wichmann et al. (2009) stated that although the air pollutant levels showed evidence of airway obstruction, the spirometric values of the participants were above the normal limits. Specifically, in this study, the lung functions were above $80 \%$ (mean predicted percent of FVC was 107.4 and for FEV1 was 91.4), both of which are considered 'healthy' in normal population. On the other hand, children with 'lowered' levels of lung function may not represent a part of 'diseased' or 'effected' population of the study. As mentioned above, the lung function tests are used to describe the lung functionality and the subject values are compared with the predicted values obtained from the healthy population of comparable age, gender, ethnicity, and height.

The normality and abnormality of the lung function tests also depend upon the number and type of the lung function tests. Though the use of fewer tests while assessing the lung function is economical and time-efficient, it increases the chances of false positives. Hence, the spirometry tests conducted in exposed subjects could be misinterpreted, especially if performed without the 
knowledge of prior disease in the patient. A study done by Vedal et al. (1983) showed that when few tests (FVC, FEV1 FEV1/FVC) were performed, about $10 \%$ of the study participants had at least one abnormal test performance. When full 14 spirometry tests were performed, about $24 \%$ of the subjects had at least one abnormal test result, with each test having a $5 \%$ false positive rate. Boezen et al. (1998) study showed that with increase in air pollution levels, the prevalence of respiratory symptoms increased significantly in respiratory compromised patients though no such significance was found in population without respiratory complications. Another study by Knudson et al. (1976) noted that when one of the respiratory parameter was abnormal, the entire flow volume curve was effected. Overall, the appropriate use of the pulmonary function tests depends upon the accurate interpretation of the tests and not merely on the percentage values of the lung functions.

The epidemiological studies have assessed the role of air pollutants in relation to population exposure. The studies which have assessed the role of acute exposure, have related the small time changes in exposure to the acute adverse effects. Typically, the exposure is estimated as an ambient air exposure and not the personal exposure. Gauderman et al. (2005) studied the effect of ambient air pollution on the growth of lung function and change in FEV1 for population ranging from 10 to 18 years for a period of eight years. The study stated that the exposure to ambient air pollution led to significant deficits in the FEV1 values of 18-year-old subjects. Similarly, Jedrychowski et al. (1999) study in Poland found lowered lung growth and decreased FEV1 values in the preadolescent children exposed to the ambient air pollutants.

Majority of the epidemiological studies have failed to consider a threshold value, beyond which the air pollutants are bound to adversely effect the human health such as their mortality rate. A study by Cakmak et al. (1999) attempted to detect the threshold values for the ambient air 
pollutants in time series studies, which have measured the association of the air pollutants with the adverse health effects. The study reported an uncertainty in estimating the threshold with an increased degree of error. Watt M et al. (1995) studied the differences in personal exposure and the ambient air pollutant concentration in the two groups of traffic wardens exposed to air pollution. The study found significant difference between the personal exposure and the area exposure levels and concluded that measuring the ambient air concentrations would be of limited value when evaluating the effects of exposure on the individual health effects. Moreover, based on the conditions, there might be varied threshold levels of adverse health effects from the ambient area concentrations. Epidemiological studies have also demonstrated that the inadequate exposure measurements may lead to differential effect estimates, especially in the studies utilizing fewer monitors in selected locations and presuming it to represent a larger geographical area with varied population statistics. Goldstein and Landovitz, 1997 recommended that using a single monitoring station is inadequate to measure the short term variations in the air pollution. Most epidemiological studies including the Wichmann et al. (2009) study evaluated the relationship of daily average variations in pollutants using limited monitors, which is not representative of a wide geographical region.

\subsection{Conclusion}

The current study concluded that the emissions from a calcining facility (Copetro) are well below the standards laid down by the regulatory agencies to protect the public health. Further, if the calcining facility is operated and maintained within the specified control measures, it is a de minimis contributor of air emissions in the community. It is likely that the epidemiological studies 
assigning higher risk to the emissions from a calcining facility, might have included other sources of pollution such as automobiles, construction sites etc.

Air pollution studies are plagued by the presence of unknown confounders in the air which might skew the statistical analysis and results of the studies. Studies, especially with a crosssectional design perform one-time measurement of an air pollutant, and are thus inadequate to quantify the amount of air pollutants such as particulate matter associated with the adverse health effects such as changes in lung functions. In other words, although these studies have reported on the associations between air pollutants and their respective ill-effects, the studies failed to describe the extent of contact with air pollutants in the exposed and unexposed population. Furthermore, it is difficult to assign the exposure to subjects divided into cases and controls and may thus lead to misclassification of 'disease' and 'non-disease' rates in the community. Peng et al. (2009) found that PM2.5 is the major constituent of the Particulate matter responsible for higher hospitalization rates reported in the epidemiological studies. Dominici et al. (2006) calculated the hospital admission rates associated with PM2.5 and found a short term positive relationship with the prevalence of respiratory diseases. However, similar studies encounter various confounders (publication bias, regional variability and misclassification of disease) and are thus questionable while assigning the individual health exposure and risk. Overall, it is difficult to assign specific ill-effects to a particular source such as Petrochemical industry, since we cannot ascertain the individual exposure. In this case, further information is required to study the emissions from the source to associate it with the respiratory health effects. As noted above, the levels of emissions from the Calcining industry are below the regulatory limits and it is difficult to demonstrate any threshold limit to the air pollutants, as definite association of air pollution from Petrochemical industry with adverse respiratory effects is inconsistent. It has been usually debated as to what 
extent the exposure data represent the actual exposure to outcome indicators (change in lung function, asthma exacerbations) as well as the differences in the study population (cases or controls, exposed or non-exposed). In addition to inadequate assessment of the exposure, the epidemiological studies also vary on the methods for the study population selection (depending upon the exposure), which may further confound the association between the exposure and the outcome. The risk assessment of the air pollutants would depend upon the meaningful and clear diagnostic criteria which would have the analytic power in obtaining reliable exposure measurements. 


\section{REFERENCES}

Atkinson, R. W., et al., 1999. Short-term associations between outdoor air pollution and visits to accident and emergency departments in London for respiratory complaints. European Respiratory Journal 13.2: 257-265.

Boezen, M. et al., 1998. Peak expiratory flow variability, bronchial responsiveness, and susceptibility to ambient air pollution in adults. American journal of respiratory and critical care medicine,158(6), pp.1848-1854.

Belli, S. et al., 2004. Case-control study on cancer risk associated to residence in the neighborhood of a petrochemical plant. European Journal of Epidemiology, 19(1), 49-54.

Birghila, S. et al., 2011. Study on physical-chemical properties of petroleum cokes. Romanian Journal of Physics, 56(7-8), pp.976-82.

Brunekreef, B., Dockery, D. W., \& Krzyzanowski, M. 1995. Epidemiologic studies on shortterm effects of low levels of major ambient air pollution components. Environmental Health Perspectives, 103(Suppl 2), 3.

Cakmak, S., Burnett, R. T., \& Krewski, D. 1999. Methods for detecting and estimating population threshold concentrations for air pollution-related mortality with exposure measurement error. Risk analysis, 19(3), 487-496.

Caruso, J.A. et al., 2015. Petroleum Coke in the Urban Environment: A Review of Potential Health Effects. International journal of environmental research and public health, 12(6), pp.6218-6231.

Costantino J. P., Redmond C. K., Bearden A.1995. Occupationally related cancer risk among coke oven workers: 30 Years of follow-up. Journal of Occupational. Environmental Medicine.; 37:597-604. doi: 10.1097/00043764-199505000-00009.

Charron, A., et al., 2004. Quantitative interpretation of divergence between PM 10 and PM 2.5 mass measurement by TEOM and gravimetric (Partisol) instruments. Atmospheric Environment,38(3), pp.415-423.

Chau N. et al., 1993. Mortality in retired coke oven plant workers. British Journal of Industrial. Medicine.; 50:127-135. doi: 10.1136/oem.50.2.127. 
Clark C. R. et al., 2013. A GHS-consistent approach to health hazard classification of petroleum substances, a class of UVCB substances. Regulatory Toxicology and Pharmacology 67; 409-420

Davies G. M. A. 1997. mortality study of coke oven workers in two South Wales integrated steelworks. British Journal of Industrial Medicine; 34:291-297. doi: 10.1136/oem.34.4.291.

de Moraes, et al., 2010. Wheezing in children and adolescents living next to a petrochemical plant in Rio Grande do Norte, Brazil. Jornal de pediatria,86(4), pp.337-344.

Divine, B.J., Hartman, C.M, and Wendt, J.K. 1999a. Update of the Texaco mortality study 194793: Part I. Analysis of overall patterns of mortality among refining, research, and petrochemical workers. Occupational and Environmental Medicine 56: 167-173.

Dominici, F. et al., 2006. Fine particulate air pollution and hospital admission for cardiovascular and respiratory diseases. JAMA 295.10 (2006): 1127-1134.

Dominici, F. et al., 2003. Shape of the exposure-response relation and mortality displacement in the NMMAPS database. In: Revised analyses of time-series studies of air pollution and health, Special Report. Health Effects Institute, Boston, MA. pp. 91-96.

Edwards L, 2015. The History and Future Challenges of Calcined Petroleum Coke Production and Use in Aluminum Smelting. JOM, 67(2), pp.308-321.

Frye, C. et al., 2003. Association of lung function with declining ambient air pollution. Environmental Health Perspectives 111.3: 383.

Gauderman, W. James, et al. 2005. Childhood asthma and exposure to traffic and nitrogen dioxide. Epidemiology 16.6: 737-743.

Goldstein IF, Landovitz L Analysis of air pollution patterns in New York City. Il: Can one aerometric station represent the area surrounding it? Atmospheric Environent 11:53-57 (1977).

Hasanbeigi A, et al. 2013. Quantifying the co-benefits of energy-efficiency policies: a case study of the cement industry in Shandong Province, China. Science of the total environment 458 (2013): 624-636.

Hepler, D.I., Beck, L.S., and Wingate, D.A. 1982. Carcinogenic potential of petroleum cokes and process products. 2. Bioassay. In: The Toxicology of Petroleum Hydrocarbons, H.N MacFarland, C.E. Holdsworth, J.A. MacGregor, R.W. Call, and M.L. Kane Washington, D.C: American Petroleum Institute, pp. 227-232. 
$\mathrm{Hu}, \mathrm{Y}$. et al., 2006. Increased risk of chronic obstructive pulmonary diseases in coke oven workers: interaction between occupational exposure and smoking. Thorax, 61(4), pp.290-295.

Huntingdon Life Sciences. 1999. Study number 97-6119. Calcined coke (F284) and green coke (F-285): Fibrogenic screening study in the rat. Report submitted to ARCO, October 20, 1999.

Hurley J.F et al., 1983. The mortality of coke workers in Britain. American Journal Industrial Medicne.; 4:691-704. doi: 10.1002/ajim.4700040603.

Ilabaca, M. et al., 1999. Association between levels of fine particulate and emergency visits for pneumonia and other respiratory illnesses among children in Santiago, Chile. Journal of the Air \& Waste Management Association 49.9: 154-163.

Jedrychowski, Wieslaw, Elzbieta Flak, and Elzbieta Mróz. 1999. The adverse effect of low levels of ambient air pollutants on lung function growth in preadolescent children. Environmental Health Perspectives 107.8 (1999): 669.

Kaldor, J. et., 1984. Statistical association between cancer incidence and major-cause mortality, and estimated residential exposure to air emissions from petroleum and chemical plants. Environmental Health Perspectives, 54, 319.

Keller, A. et al., 2012. Does the perception that stress affects health matter? The association with health and mortality. Health psychology, 31(5), 677.

Klonne, et al., 1987. Two-year inhalation toxicity study of petroleum coke in rats and monkeys. American Journal of Industrial Medicine 11: 375-389.

Knudson, R. J., et al., 1976. The Maximal Expiratory Flow-Volume Curve: Normal Standards, Variability, and Effects of Age 1, 2. American Review of Respiratory Disease 113.5: 587600 .

Lewis, R.J. et al., 2003. Mortality and cancer morbidity in a cohort of Canadian petroleum workers. Occupational. Environmental Medicine.; 60:918-928. doi: 10.1136/oem.60.12.918

Lipscomb, J. and Lee, S. 1983. Health Hazards Evaluation Report No. HETA 81-421-1251. Great Lakes Carbon Corp. Port Arthur, Texas. U.S. National Institute for Occupational Safety and Health, Cincinnati, OH. August.

Loyo-Berríos, N.I., Irizarry, R., Hennessey, J.G., Tao, X.G., Matanoski, G., 2007. Air pollution sources and childhood asthma attacks in Cataño, Puerto Rico. American. Journal of Epidemiology. 165, 927-935.

Loyo-Berríos, N.I., Orengo, J. C., \& Serrano-Rodríguez, R. A. 2006. Childhood asthma 
prevalence in northern Puerto Rico, the Rio Grande, and Loiza experience. Journal of Asthma, 43(8), 619-624.

Luginaah, I.N. et al., 2000. A longitudinal study of the health impacts of a petroleum refinery. Social science \& medicine, 50(7), pp.1155-1166.

Maestrelli, P. et al., 2011. Personal exposure to particulate matter is associated with worse health perception in adult asthma. Journal of Investigational Allergology \& Clinical Immunology, 21(2), 120-8.

McKee et al., 2014. Toxicological Assessment of Green Petroleum Coke. International Journal of Toxicology 2014, Vol. 33(Supplement 1) 156S-167S

Meo, S.A. et al., 2015. Lung function and fractional exhaled nitric oxide among petroleum refinery workers. Journal of Occupational Medicine and Toxicology, 10(1), p.37.

Nakata C, et al., 2011. Growth and physiological responses of Triticum aestivum and Deschampsia caespitosa exposed to petroleum coke. Water Air Soil Pollution; 216(14):59-72.

Mudu P, Terracini B, Martuzzi M, eds 2014. Human Health in Areas with Industrial Contamination. Copenhagen: WHO Regional Office for Europe.

Mukesh S. et al., 2004. Effects of Particulate Air Pollution on the Respiratory Health of Subjects Who Live in Three Areas in Kanpur, India, Archives of Environmental Health: An International Journal, 59:7, 348-358, DOI: 10.3200/AEOH.59.7.348-358

Peng, R. D., et al., 2009. Emergency admissions for cardiovascular and respiratory diseases and the chemical composition of fine particle air pollution. Environmental Health Perspectives, 117(6), 957.

Pasetto, R., Comba, P., \& Pirastu, R. 2008. Lung cancer mortality in a cohort of workers in a petrochemical plant: occupational or residential risk? International journal of occupational and environmental health, 14(2), 124-128.

Pope, C.A., et al., 2002. Lung cancer, cardiopulmonary mortality, and long-term exposure to fine particulate air pollution. Journal of the American Medical Association 287: 1132-41.

Redmond, C.K. 1983. Cancer mortality among coke oven workers. Environmental Health Perspective., 52, 67-73

Rovira et al., 2014. Asthma, respiratory symptoms and lung function in children living near a petrochemical site. Environmental Research 133: 156-163.

Rusconi, F. et al., 2011. Asthma symptoms, lung function, and markers of oxidative stress and inflammation in children exposed to oil refinery pollution. Journal of Asthma 48, 84-90, 
http://dx.doi.org/ 10.3109/02770903.2010.538106.

Sakabe H., Tsuchiya K., Takekura N. 1975. Lung cancer among coke oven workers: A report to labor standard Bureau, ministry of labor. Japan. Industrial Health; 13:57-68. doi: 10.2486/indhealth.13.57.

Sans, S. et al., 1995. Cancer incidence and mortality near the Baglan Bay petrochemical works, South Wales. Occupational and Environmental Medicine, 52(4), 217-224.

Santos, Aldo Ramos, Rogério José da Silva, and Maria Luiza Grillo Renó. 2015. Analysis of Petroleum Coke Consumption in Some Industrial Sectors. Journal of Petroleum Science Research

Schwartz, J. et al., 1996. Is daily mortality associated specifically with fine particles?. Journal of the Air \& Waste Management Association, 46(10), pp.927-939.

Simonsen, N., Scribner, R., Su, L. J., Williams, D., Luckett, B., Yang, T., \& Fontham, E. T. (2010). Environmental exposure to emissions from petrochemical sites and lung cancer: the lower Mississippi interagency cancer study. Journal of environmental and public health, 2010.

Smargiassi, A. et al., 2009. Risk of asthmatic episodes in children exposed to sulfur dioxide stack emissions from a refinery point source in Montreal, Canada. Environmental Health Perspectives, 117(4), 653-9. doi:10.1289/ehp.0800010

United States Environmental Protection Agency (US EPA). (2004). Air Quality Criteria for Particulate Matter. National Center for Environmental Assessment. EPA/600/P-99/002aF. October.

United States Environmental Protection Agency (USEPA). (2006). National Ambient Air Quality Standard for Particulate Matter. 71 Federal Register p.61144. October 17.

Vedal, S. et al., 1983. Air-pollution effects on children's respiratory symptoms and peak expiratory flow. American review of respiratory disease. vol. 127. no. 4.

Ware, J.H. et al., 1993. Respiratory and irritant health effects of ambient volatile organic compounds. The Kanawha County Health Study. American Journal of Epidemiology. 137, $1287-1301$.

Watt, M. et al. 1995. Individual exposure to particulate air pollution and its relevance to thresholds for health effects: a study of traffic wardens. Occupational and environmental medicine 52.12 (1995): 790-792.

White, N. et al., 2009. Meteorologically estimated exposure but not distance predicts asthma symptoms in schoolchildren in the environs of a petrochemical refinery: a crosssectional study. Environmental Health: A Global Access Science Source, 8(1), 45. 
doi: 10.1186/1476- 069X-8-45

Wichmann, F. A. et al., 2009. Increased asthma and respiratory symptoms in children exposed to petrochemical pollution. The Journal of Allergy and Clinical Immunology, 123(3), 632- 8. doi: 10.1016/j.jaci.2008.09.052

World Health Organization (WHO) 2005. WHO air quality Guidelines global update. Report on a Working Group Meeting, Bonn, Germany, October 18-20.

Wu W. 1998. Occupational cancer epidemiology in the People's Republic of China. Journal of Occupational Medicine.1988; 30:968-74. doi: 10.1097/00043764-198812000-00017.

Yang, C.Y., Chang, C.C., Chuang, H.Y., Ho, C.K., Wu, T.N., Chang, P.Y., 2004. Increased risk of preterm delivery among people living near the three oil refineries in Taiwan.

Environmental International. 30, 337-342 